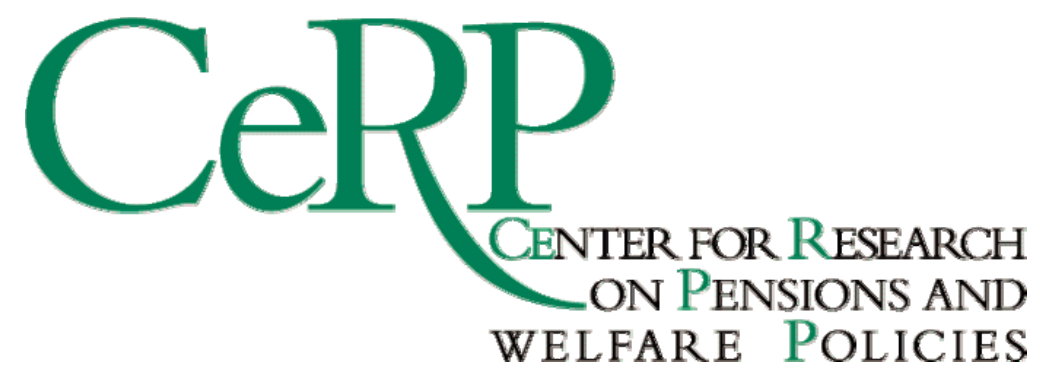

Working Paper 80/08

\title{
LEARNING, AMBIGUITY AND LIFE-CYCLE PORTFOLIO ALLOCATION
}

\author{
Claudio Campanale
}




\title{
Learning, Ambiguity and Life-Cycle Portfolio
}

\section{Allocation*}

\author{
Claudio Campanale
}

October 10, 2008

\footnotetext{
* Claudio Campanale, Departamento de Fundamentos del Análisis Económico, Universidad de Alicante, Campus San Vicente del Raspeig, 03690, Alicante, Spain. Phone: +34 965903614 ext. 3262. E-mail: claudio@merlin.fae.ua.es.

I wish to thank Samuel Bentolila, Paolo Ghirardato, Francisco Gomes, Antonio Mele, Filippo Taddei and seminar participants at the University of Vigo, the University of Turin - Collegio Carlo Alberto and the participants to the Econometric Society North American Meetings 2008 for discussion and suggestions. I also wish to thank the Ministerio de Educación y Ciencia proyecto SEJ 2007-62656 and IVIE for financial support and CeRP for generous hospitality during the development of this project. Any remaining errors or inconsistencies are entirely my responsibility.
} 


\begin{abstract}
In the present paper I develop a life-cycle portfolio choice model where agents perceive stock returns to be ambiguous and are ambiguity averse. As in Epstein and Schneider (2005) part of the ambiguity vanishes over time as a consequence of learning over observed returns. The model shows that ambiguity alone can rationalize moderate stock market participation rates and conditional shares with reasonable participation costs but has strongly counterfactual implications for conditional allocations to stocks by age and wealth. When learning is allowed, conditional shares over the life-cycle are instead aligned with the empirical evidence and patterns of stock holdings over the wealth distribution get closer to the data.
\end{abstract}

Keywords: Portfolio choice, life-cycle, ambiguity, learning

JEL codes: G11, D91, H55 


\section{Introduction}

The last decade has witnessed a substantial surge of academic interest in the problem of households' financial decisions, perhaps triggered by the increased importance of personal savings for retirement consumption that is taking place in response to the debate about downsizing the role of unfunded social security. A number of empirical facts have been documented regarding in particular the stockholding behavior of households. These include the fact that participation rates, even though increasing over the years, are still at about half of the population and the moderate share allocated to stocks by participants. It has also been documented that the share of financial wealth allocated to stocks is increasing in wealth and roughly constant or moderately increasing in age. ${ }^{1}$ Equally important has been the development of theoretical models that, based on a workhorse of modern macroeconomics, that is, the precautionary savings model, have tried to explore the same issue. The current paper joins this latter line of research by exploring the role of a class of non standard preferences in the context of the model cited above.

More specifically, in this paper I present a model of life-cycle portfolio choice where agents perceive the return to one of the assets to be ambiguous and are averse to ambiguity. As in Epstein and Schneider (2005) ambiguity can be reduced over time through learning. The basic framework of the model

\footnotetext{
${ }^{1}$ Among the papers that have uncovered the patterns of household financial behavior are Ameriks and Zeldes (2004), Bertaut and Starr-McCluer (2000), Curcuru et al. (2004) and Heaton and Lucas (2000) for the US. The book of Guiso et al. (2001) documented the same facts for a number of other industrialized countries as well and the work by Calvet, Campbell and Sodini (2007) has gone in much greater details to document stock-holding behavior among Swedish households.
} 
is otherwise standard: agents have finite life and receive a stochastic earnings stream during working life, followed by a constant pension benefit in retirement. Agents cannot insure against earnings uncertainty, thus use savings as a selfinsurance instrument. Beside that they save for the other usual reasons, that is, to finance consumption during retirement, to insure against uncertainty about the length of life and to leave a bequest. Saving can occur through two assets, a risk-free bond and a risky stock, and exogenous no borrowing and no short sale constraints are imposed. Trading in the stock requires payment of a fixed per period cost. Where the model departs from the basic framework is in the way agents perceive the stock return process. In this regard the model assumes that agents perceive the stock return process to be ambiguous, that is, they think they cannot know the exact distribution governing that process but think it lies in some set of distributions. Agents are averse to ambiguity according to the max-min utility model developed by Gilboa and Schmeidler (1989) in a static framework and extended to a dynamic setting by Epstein and Schneider (2003). It is also assumed that the ambiguity present in the stock return process can be reduced through the observations of the realized returns and that stock market participants have an advantage at doing so.

The model is solved numerically and its properties are analyzed under a broad set of parameters. It is shown that ambiguity aversion alone can generate moderate participation rates and conditional shares without resorting to large participation costs and it does so by assuming a fairly reasonable amount of ambiguity in the stock return process. On the other hand the model with ambiguity but no learning shows two very counterfactual properties when we look deeper at its implications: stock shares for market participants are strongly declining in 
both age and wealth which is at odd with the empirical evidence. When learning is introduced, the model, while retaining reasonable average participation rates and conditional shares, generates a life-cycle profile of conditional stock allocation that is slightly increasing but with little variation as in the data. It also displays constant stock shares over wealth levels, thus moving a step in the right direction towards matching the empirically observed increasing pattern.

The main contribution of the paper is to document the implications of ambiguity aversion and learning in an ambiguous environment for household life-cycle portfolio allocation and to show that these features may have an important role in explaining the observed pattern of household financial choices. In doing so it joins two very active lines of research. The first one is the literature on portfolio allocation in precautionary savings models. This literature was first explored by Heaton and Lucas (1997 and 2000) and Haliassos and Michaelides (2003) in an infinite horizon setting and by Campbell et al. (2001), Cocco, Gomes and Maenhout (2005) and Gomes and Michaelides (2005) in a life-cycle setting. These papers documented the basic properties of this type of model and pointed out the difficulties it has to explain the low participation rates and conditional stock shares observed in the data, in some cases proposing possible solutions. More recently a number of papers and in particular the ones by Benzoni et al. (2007), Lynch and Tan (2008) and Wachter and Yogo (2008) have looked for explanations of patterns of household stock market investment over the lifecycle and over wealth levels. The second one is the growing literature that has studied the implications of model uncertainty in asset pricing and portfolio choice. Contributions in a dynamic framework go back to Epstein and Wang (1994). More recently Cao, Wang and Zhang (2005) explored the implications 
of heterogeneity in ambiguity aversion for stock market participation and the equilibrium equity premium in a static framework and Leippold, Trojani and Vanini (2005) studied a dynamic Lucas-style exchange economy with both ambiguity and learning. While the three papers cited above used the max-min model of ambiguity aversion, Ju and Miao (2007) introduced the Klibanoff, Marinacci and Mukerji (2006) smooth ambiguity model in a dynamic endowment economy with learning about the hidden state and showed that the model can match a wide set of asset pricing facts. Model uncertainty has also been studied in the alternative framework of robust control of which two applications to asset pricing are Maenhout (2004) in an endowment economy and Cagetti et al. (2002) in a business cycle model. Examples of explorations of the role of ambiguity aversion in portfolio choice models are Garlappi, Uppal and Wang (2006) that use a static mean-variance approach and the same paper by Maenhout cited above. This latter paper is dynamic as the present one, however it omits labor income and uses the robust control approach.

The rest of the paper is organized as follows. In Section 2 I present the description of the model, in Section 3 I report the choice of parameters, in Section 4 I report the main findings of the analysis and finally in Section 5 some short conclusions are outlined. The paper is completed by an Appendix where a short description of the numerical methods used to solve the model is provided. 


\section{The Model}

\subsection{Demography and Preferences}

Time is discrete and the model period is assumed to be 1 year. Adult age is denoted with the letter $t$ and can range from 1 to $T=80$ years. Agents are assumed to enter the model at age 20 so that real life age is equal to $t+20$. Each agent faces an age changing conditional probability of surviving to the next period which will be denoted with $\pi_{t}$. Surviving agents work the first 45 years and retire afterwards.

Agents do not value leisure, hence they derive utility from the stream of consumption they enjoy during their life-time only. Utility over consumption is defined by a period utility index $u\left(c_{t}\right)$ which will be assumed to be of the standard iso-elastic form. Agents also derive utility from leaving a bequest; the bequest motive is of the so called warm glow form hence can be simply represented by a function $D($.$) defined over terminal wealth.$

In the economy there are two independent sources of uncertainty. The first one is determined by the stochastic process for labor earnings and it is standard in that I assume that agents know its distribution. This process will be described in a later subsection. The second one is the process for stock returns. Following Epstein and Schneider (2005) it is assumed that this process is i.i.d. and that agents perceive it as ambiguous. In other words they assume that stock returns may be drawn from a whole family of distributions and even if they can learn from past observations of realized returns, they can never shrink the set of distributions to a singleton.

In every period an element $h_{t} \in H$ is observed: this pair consists of a 
realization of the stock return $w_{t} \in W$ and a realization of the labor efficiency unit shock $z_{t} \in Z$. At age $t$ then the agent's information set consists of the history $h^{t}=\left(h_{1}, h_{2}, \ldots, h_{t}\right)$. Given that the horizon is finite the full state space will be $H^{T}$. The agent ranks consumption plans $c=\left\{c_{t}\right\}$ where consumption $c_{t}$ depends on the history $h^{t}$. At any age $t=1,2, \ldots \ldots ., T$ and given history $h^{t}$, the agent's ordering of consumption plans is represented by a conditional utility function $U_{t}$ defined recursively by:

$$
U_{t}\left(c ; h^{t}\right)=\min _{p \in \mathcal{P}_{t}\left(w^{t}\right)} E^{p}\left[u\left(c_{t}\right)+\beta E^{z_{t+1}} U_{t+1}\left(c ; h^{t+1}\right)\right]
$$

where $\beta$ and $u$ are defined above. The set of probability measures $\mathcal{P}_{t}\left(w^{t}\right)$ models beliefs about the next realization of the stock return process $w_{t+1}$ given history up to $w_{t}$. When this set is a non-singleton such beliefs reflect ambiguity and the minimization over $p$ reflects ambiguity aversion. ${ }^{2}$ The set of probability measures $\{\mathcal{P}\}$ is called process of conditional one-step ahead beliefs and together with $u(\cdot)$ and $\beta$ constitute the primitives of the functional form.

\subsection{Learning}

The investor knows the distribution of future labor earnings, however he perceives stock returns as ambiguous. In particular he thinks that they are generated by the same memoryless mechanism in each period and that even if there are features of the data generating process that can be learned others are not. ${ }^{3}$ Mathematically learning is represented by a tuple $\left(\Theta, \mathcal{M}_{0}, \mathcal{L}, \alpha\right)$ where $\Theta$ is a parameter space whose elements $\theta$ represent features of the data generating pro-

\footnotetext{
${ }^{2}$ The minimization is taken with respect to $p$ only since the process for labor earnings is independent and is not ambiguous.

${ }^{3}$ In this subsection I present a minimal exposition of the subject which is entirely based on Epstein and Schneider (2005) to which the reader is referred.
} 
cess that the agents think are learnable. The set $\mathcal{M}_{0}$ is the set of priors on $\Theta$ and $\mathcal{L}$ is a set of likelihood functions whose multiplicity reflects the existence of poorly understood factors driving the returns. Finally $\alpha$ is a parameter that governs the reevaluation process through which posteriors are constructed based on the past observed returns. The set of posteriors is constructed based on a likelihood ratio test and will be defined as:

$$
\begin{aligned}
\mathcal{M}_{t}^{\alpha}\left(w^{t}\right)= & \left\{\mu_{t}\left(w^{t} ; \mu_{0} \in \mathcal{M}_{0}, \ell^{t} \in \mathcal{L}^{t}\right) \mid\right. \\
& \left.\int \prod_{j=1}^{t} \ell_{j}\left(w_{j} \mid \theta\right) d \mu_{0}(\theta) \geq \alpha \max _{\tilde{\mu}_{0} \in \mathcal{M}_{0}, \tilde{\ell}^{t} \in \mathcal{L}^{t}} \int \prod_{j=1}^{t} \tilde{\ell}_{j}\left(w_{j} \mid \theta\right) d \tilde{\mu}_{0}(\theta)\right\} .
\end{aligned}
$$

In this specific context $\Theta$ is assumed to be a one-dimensional set with elements $\theta \in[\bar{\lambda}, 1-\bar{\lambda}]$ where $\bar{\lambda}<\frac{1}{2}$. The set of likelihoods is defined by $\ell(1 \mid \theta)=\theta+\lambda$ for some $\lambda \in[-\bar{\lambda}, \bar{\lambda}]$ and $\ell(1 \mid \theta)$ is the probability of observing a high stock return given the value of $\theta$. The set of priors $\mathcal{M}_{0}$ is given by all the Dirac measures on $\Theta$. Finally $\alpha$ is a constant that determines how the set of posteriors responds to new information: were it equal to zero the set of posteriors $\mathcal{M}_{t}$ would be equal to $\mathcal{M}_{0}$ for all $t$ and no updating would occur. A higher value of $\alpha$ implies a more stringent test so that a wider set of distribution is discarded from the set of possible posteriors which then changes more quickly in response to new observations. A value of $\bar{\lambda}>0$ is needed for returns to be ambiguous signals.

It can be proved that under the simple specification used here the set of posteriors depends on the sample only through the fraction of high stock returns $\phi_{t}$ observed before $t$. More specifically it will obey the following law:

$$
\mathcal{M}_{t}^{\alpha}\left(w^{t}\right)=\left\{\theta \in \Theta: g\left(\theta ; \phi_{t}\right) \geq \max _{\tilde{\theta} \in \Theta} g\left(\tilde{\theta} ; \phi_{t}\right)+\frac{\log (\alpha)}{t}\right\}
$$

where $g\left(\theta ; \phi_{t}\right)=\phi_{t} \log (\theta+\bar{\lambda})+\left(1-\phi_{t}\right) \log (1-\theta+\bar{\lambda})$. This specification is very 
convenient for the current problem since it only adds one state variable to the agent's optimal dynamic program, allowing it to retain numerical tractability.

\subsection{Labor Income and Pensions}

I use the indexed letter $Y_{t}$ to denote income. During working life income is determined by an uncertain stream of labor earnings. Earnings can be expressed as the product of two components:

$$
Y_{t}=G(t) z_{t}
$$

where the function $G(t)$ is a deterministic function of age meant to capture the hump in life-cycle earnings that is observed in the data. The second term, $z_{t}$, is a stochastic component that follows an $\mathrm{AR}(1)$ process in logarithms:

$$
\ln \left(z_{t}\right)=\rho \ln \left(z_{t-1}\right)+\varepsilon_{t}
$$

where $\varepsilon_{t}$ is an i.i.d. normal random variable.

In the retirement years agents receive a fixed pension benefit, so that

$$
Y_{t}=Y_{s s} .
$$

\subsection{Financial Assets}

Agents can use two different assets to carry out their investment plans. First there is a one period risk free bond with price $q$ and return $R^{f}=\frac{1}{q}$. The second asset is a risky stock. Investors perceive the return to this asset ambiguous but the actual return $R_{t+1}^{s}$ is generated by a single i.i.d. process that can take two values: $\mu \pm \delta$ with equal probability. Consequently $\mu-\frac{1}{q}$ is the average equity premium and $\delta$ is the standard deviation of the equity return. This simple 
formulation of equity returns is somewhat non-standard since in the related quantitative literature the usual assumption is of normal stock returns. It is adopted in this context because it is convenient to the model of learning about stock returns used here.

Trade in the two assets is subject to three frictions. First all households are prevented both from borrowing and from selling short stock. Denoting bond and stock-holdings with $B_{t}$ and $S_{t}$ respectively this implies:

$$
\begin{aligned}
B_{t} & \geq 0 \\
S_{t} & \geq 0 .
\end{aligned}
$$

Second, households who do participate in the stock market are subject to a minimum investment limit that I denote with $\underline{S}$, that is, the relevant constraint for them is

$$
S_{t} \geq \underline{S}
$$

Third it is assumed that participation in the stock market requires payment of a fixed cost $F_{p}$ in each period.

A further important assumption about the stock market is that in the model households that participate receive a signal about the ambiguous stock return process for sure while households who do not participate receive it only probabilistically. The letter $\xi$ will be used to denote the probability that a non stockholder can infer information about the return process from the observed realized return in any given year.

The minimum investment requirement and the differential flow of information to stock holders and non stock holders are non standard, hence require some comments. The fact that participants receive signals about the stock 
return process with greater probability than non participants can be justified based on ideas recently expressed in the "rational inattention"literature developed for example by Sims (2006) and applied to monetary theory by Mankiw and Reis (2006) and to consumer theory by Reis (2004). The key point of this theory is the observation that even though information may be in principle free, still absorbing and processing it requires the allocation of resources to it so that agents may choose to disregard it. As in Mankiw and Reis (2006) the model presented here assumes exogenously a differential flow of information to different agents rather than deriving the result from an optimal information acquisition problem. The advantage of stockholders though seems reasonable if one takes into account that stockholders may receive already processed information through their broker or other financial advisor or as a side product of activities required by stock-holding like compiling the relevant section of tax forms. More generally it is arguable that if an agent has only limited processing resources to allocate to her financial decisions she will follow more closely those assets she has in her portfolio. With respect to the minimum equity requirement observe that as long as participating in the stock market gives an informational advantage towards resolving ambiguity, as assumed here, it can be valuable to participate even if the current "worst case" equity premium is negative. This could potentially make some agents pay the fixed participation cost but hold no stocks which would be contradictory. At an empirical level this choice can be justified for example by observing that mutual fund companies and brokerage houses often impose minimum investment limits. Also some work like Heaton and Lucas (2000) study stock portfolio allocation at the empirical level conditional on stock holding being above a threshold of 500 dollars to rule 
out occasional investors.

\subsection{The Optimization Problem}

With the description of the model given above it is now possible to state the household's optimization problem in dynamic programming form. In order to make the description more readable I divide the section into two paragraphs, the first one describing the indirect utility of an agent if she chooses to participate in the stock market and the second one for an agent that chooses not to participate.

Participation Indirect Utility The indirect utility of an agent if she decides to participate in the stock market is given by the following equation:

$$
\begin{aligned}
& V_{t}^{\text {part }}\left(X_{t}, z_{t}, \phi_{t}, n_{t}\right)=\max _{c_{t}, B_{t+1}, S_{t+1}} \min _{p_{t} \in \mathcal{P}_{t}}\left\{u\left(c_{t}\right)+\right. \\
& \left.\quad+\beta E\left[\pi_{t+1} V_{t+1}\left(X_{t+1}, z_{t+1}, \phi_{t+1}, n_{t+1}\right)+\left(1-\pi_{t+1}\right) D\left(X_{t+1}\right)\right]\right\}
\end{aligned}
$$

subject to the budget constraint

$$
c_{t}+q B_{t+1}+S_{t+1} \leq X_{t}+Y_{t}-F_{p}
$$

the transition equation for financial resources

$$
X_{t+1}=B_{t+1}+R\left(w_{t+1}\right) S_{t+1}
$$

the transition equation for the fraction of time a high return was observed

$$
\phi_{t+1}\left(w_{t+1}\right)=\frac{n_{t} \phi_{t}+w_{t+1}}{n_{t}+1}
$$

, the equation describing the number of past signals about the stock return process observed

$$
n_{t+1}=n_{t}+1
$$


the inequality constraints (7) and (9) and equations (4), (5) and (6) that define the nonfinancial income available to the agent from labor earnings or pensions. The agent's state variables are the amount of financial resources $X_{t}$, the labor earnings shock $z_{t}$, the fraction of past observations on the stock return that were high $\phi_{t}$ and the number of those signals observed $n_{t}$. The agent chooses the amounts of stocks, bonds and consumption that maximize his utility but since he has max-min preferences he minimizes these optimal values with respect to $\mathcal{P}_{t}$, the set of admissible beliefs. Given the way the learning process is modeled the set $\mathcal{P}_{t}$ is defined by $\left\{(\theta, \lambda) \mid \theta \in \mathcal{M}_{t}^{\alpha}, \lambda \in[-\bar{\lambda}, \bar{\lambda}]\right\}$. The argument of the function to be maximized that we find in curly braces is the sum of the utility of current consumption plus continuation utility which in turn is given with probability $\pi_{t+1}$ - the probability of survival — by the continuation value function and with probability $1-\pi_{t+1}$ by the utility from bequests function $D\left(X_{t+1}\right)$. The expectation operator is taken with respect to the distributions $p_{t}$ and the distribution of next period labor shock conditional on the current value $z_{t}$. Inequality (11) is a standard budget constraint: it states that the expenditures in consumption, bond and stock purchases must not exceed the sum of financial resources, plus the income from earnings or pensions minus the fixed participation cost. Equation (12) describes the evolution of financial resources as the sum of one-period bonds plus stock times its gross return. This return can take a high value or low value depending on whether the state $w_{t}$ takes a value of 1 or 0 . Equation (14) shows that for an agent who decides to participate in the stock market the number of past signals on the stock return process increases by one between the current and the next period and finally equation (13) describes how, depending on whether the realized return is high 
or low, - $w_{t+1}$ equal to 1 or 0 - the past fraction of high signals observed is updated.

Non Participation Indirect Utility The indirect utility of an agent who decides not to participate in the stock market is given by the following equation:

$$
\begin{aligned}
V_{t}^{\text {nopart }}\left(X_{t}, z_{t}, \phi_{t}, n_{t}\right)=\max _{c_{t}, B_{t+1}} \min _{p_{t} \in \mathcal{P}_{t}}\left\{u\left(c_{t}\right)+\right. \\
\left.\beta E\left[\pi_{t+1} E V_{t+1}\left(X_{t+1}, z_{t+1}, \phi_{t+1}, n_{t+1}\right)+\left(1-\pi_{t+1}\right) D\left(X_{t+1}\right)\right]\right\}
\end{aligned}
$$

subject to the budget constraint

$$
c_{t}+q B_{t+1} \leq X_{t}+Y_{t}
$$

the law of motion of financial resources

$$
X_{t+1}=B_{t+1}
$$

the law of motion of the fraction of past high signals on the stock return process

$$
\phi_{t+1}= \begin{cases}\phi_{t} & \text { with probability } 1-\xi \\ \frac{n_{t} \phi_{t}+w_{t+1}}{n_{t}+1} & \text { with probability } \xi\end{cases}
$$

and the law of motion of the past number of signals observed

$$
n_{t+1}= \begin{cases}n_{t} & \text { with probability } 1-\xi \\ n_{t}+1 & \text { with probability } \xi\end{cases}
$$

As it can be seen the problem has the same state variables as the one of an agent who chooses to participate and the maximization on the right hand side of equation (15) differs from the analogous equation (10) only in that the maximization is performed on consumption and bonds with the amount of stocks being zero by definition. Also notice that the minimization with respect to the distributions in the set $\mathcal{P}_{t}$ must take place even if the agent does not buy stocks. This is 
because the investor is still exposed to ambiguity through the probability that a signal about the stock market return process is observed. The budget constraint (16) simply states that for a non participant expenditures on consumption and bonds must not exceed income from labor or pensions plus financial resources and the law of motion (17) expresses that fact that for a non stockholder financial resources next period coincide with the amount of one period risk-free bonds purchased in the current period. The last two laws of motion reflect the probabilistic receipt of a signal about the stock return generating process by an agent who does not participate in the stock market. With probability $\xi$ the agent receives the signal, hence the number of past observations received grows by one and the fraction of those that were high is updated based on the value of the shock $w_{t}$. With probability $1-\xi$ the investor does not observe a signal so that both the number of observations and the fraction of those that were high stay constant at their current value $\phi_{t}$ and $n_{t}$.

Finally the household's optimal value function will result by taking the maximum of the indirect utility from participating and from not participating in the stock market:

$$
V_{t}\left(X_{t}, z_{t}, \phi_{t}, n_{t}\right)=\max \left\{V_{t}^{\text {nopart }}\left(X_{t}, z_{t}, \phi_{t}, n_{t}\right), V_{t}^{\text {part }}\left(X_{t}, z_{t}, \phi_{t}, n_{t}\right)\right\} .
$$

The problem has no analytical solution so that numerical methods are used to examine its properties. The solution procedure consists of two parts: first decision rules are computed from the agent's dynamic programming problem; second these decision rules are used, together with random draws of the stochastic variables, to compute life-cycle profiles for 1000 agents. The simulation is repeated 30 times and the reported results are obtained by averaging over those repetitions. More details about the solution method are given in the Appendix. 


\section{Parameter Calibration}

\subsection{Preferences Parameters}

Preferences are defined by the functional form and parameters of the period utility index and the function defining the utility of bequests plus the subjective discount factor. The utility index is chosen to be of the standard iso-elastic form:

$u\left(c_{t}\right)=\frac{c_{t}^{1-\sigma}}{1-\sigma}$ and a baseline value of 2.5 is chosen for $\sigma$, the coefficient of relative risk aversion. A sensitivity analysis on this parameter will be performed, using values of 1.5 and 3.5 as well. These values are somewhat lower than those typically used in the life-cycle portfolio choice literature but more in line with the preferred values of macroeconomic studies. The utility of bequest function is defined as $D\left(X_{t+1}\right)=d \frac{\left(X_{t+1} / d\right)^{1-\sigma}}{1-\sigma}$, that is, I use the same functional form and curvature of the utility index. The additional parameter $d$ which sets the strength of the bequest function is taken to be 2.5 , one of the values used by Gomes and Michaelides (2005) who also use the same functional form. The subjective discount factor $\beta$ is set equal to 0.95 a value commonly used in the macro and finance literature. The effective discount rate is determined also by the conditional survival probabilities which are taken from the male survival probabilities available at the "Berkeley Mortality Database".4

\subsection{Learning Parameters}

The process for learning is characterized by three quantities: the long run ambiguity, the initial ambiguity and the speed at which the agents are willing to get rid of ambiguity over the life-cycle by incorporating the new information

\footnotetext{
${ }^{4}$ The database is available at the website http://www.demog.berkeley.edu/ bmd/.
} 
contained in the sequence of realized stock returns. For this reason we need to specify three parameters to fully describe the features of learning in this ambiguous environment. The long run ambiguity, that is the component of ambiguity that the agent thinks he cannot get rid of even in the long run - i.e. asymptotically — is entirely fixed by the parameter $\bar{\lambda}$ whose value I fix at 0.01 . Following Epstein and Schneider (2005) this value implies that in the long run the set of posteriors of the probability of high stock returns shrinks to $[0.49,0.51]$ which implies a range of equity premia of 64 basis points. This number seems sufficiently small to leave substantial scope for learning in the model. The speed at which the agent is willing to get rid of ambiguity is governed by the parameter $\alpha$ and its value is taken to be 0.2 in the baseline case. Finally, once the speed of learning is fixed, I determine the initial extent of ambiguity perceived in the data by assuming that prior to entering the model agents observed a certain number of stock return realizations that follow exactly the data generating process, that is, are 50 percent high and 50 percent low. The number of such observations is fixed at 20 in the baseline case. It should be stressed that this statement is only technical in nature, that is, it only serves the purpose of fixing initial ambiguity and should not be taken literally as to imply that the agent observed stock market realizations prior to entering the model. ${ }^{5}$ Under the parameters chosen the initial set of posteriors of the probability of high stock returns is the interval [0.30336, 0.69662]; with such an interval the difference between the maximum and minimum expected equity premium implied by the agent's set of beliefs is 12.58 percentage points wide. Since there is no direct evidence on

\footnotetext{
${ }^{5}$ In principle one could think that the agent got some information about the stock market process from family members, neighbors or other sources during childhood or teen-age but I don't want to stick to that interpretation.
} 
which one can base the choice of these two parameters a sensitivity analysis will be performed on both the speed of updating and the initial ambiguity. Also empirical evidence to support the claim that the extent of ambiguity over the life-cycle implied by this choice of parameters is reasonable will be discussed in the result section.

\subsection{Labor Income and Pensions}

The specification of the labor earnings process during working life requires fixing two sets of parameters. The first one refers to the function $G(t)$ which defines the deterministic hump-shaped component of earnings. This function is assumed to be a third degree polynomial in age and the coefficients are taken form the estimates by Cocco, Gomes and Maenhout (2005) for high school graduates. These estimates when aggregated over five year groups are also consistent with the ones of Hansen (1993) based on the whole population. The second one is the idiosyncratic component $z_{t}$ which is assumed to follow an $A R(1)$ process with autocorrelation coefficient $\rho=0.95$ and a standard deviation of the innovation $\sigma_{\varepsilon}=0.158$, both values taken from Hubbard, Skinner and Zeldes (1994).

During retirement it is assumed that agents receive a fixed pension benefit equal to 68 percent of average lifetime earnings conditional on the last year of earnings. The replacement ratio implicit in this formula is chosen based on Gomes and Michaelides (2005).

\subsection{Asset Returns and Fixed costs}

The bond price is set at 0.98 which implies a risk free return of about 2 percent annually. The stock return process is modeled as a two point i.i.d. process 
with the expected value $\mu$ set at 7.5 percent percent annually and a standard deviation $\delta$ of 16 percent. The value of the risk free rate is close to but a little lower than what reported in Cecchetti et al. (2000) and a little higher than what other authors in the asset pricing literature have used. ${ }^{6}$ The equity premium of 5.5 percent is a little below the values used in that literature that range from 5.75 in Cecchetti et al. (2000) to about 8 percent in Lettau (2003). As in other work on life-cycle portfolio allocation the use of a reduced equity premium may be thought to proxy for the existence of proportional transaction costs that the agent normally has to pay even after paying the fixed participation cost and that, if modeled explicitly, would add a non trivial extra burden on the numerical solution of a problem that is already quite demanding. ${ }^{7}$

Empirical work that tried to measure the magnitude of fixed stock market participation costs found values in the range of 50 to 200 dollars. ${ }^{8}$ The cost in the model is then set so that when compared to model wages it is consistent with values at the lower end of that interval.

The minimum equity investment is set at about 4 percent of average annual earnings in the economy. Assuming a plausible 35000 dollar average earnings this would be equivalent to 1400 dollars, a value in line with the minimum investment requirement at several large mutual fund companies. ${ }^{9}$ As a robustness check the model was also solved assuming a smaller and larger minimum

\footnotetext{
${ }^{6}$ See for example Mehra and Prescott (1985) or Lettau (2003) and Campanale et al. (2007).

${ }^{7}$ The choice to use a reduced equity premium can be found for example in Campbell et al. (2001), Cocco, Gomes and Michaelides (2005) and Gomes and Michaelides (2005).

${ }^{8}$ See Paiella (2001) and Vissing-Jørgensen (2002)

${ }^{9} \mathrm{I}$ performed a casual search of some large mutual fund companies' web-sites and found that they impose such requirements and that they range from $250 \$$ at American Funds to 3000 $\$$ at Vanguard. The latter also provides brokerage services and imposes the same minimum investment on those.
} 
requirement of approximately 2.25 and 5.75 percent average annual earnings. Since the results are very similar to the baseline case they won't be reported.

Finally, to complete the description of the parameters concerning the assets in the economy we need to specify the probability with which agents that do not participate in the stock market get a signal about the process generating equity returns. Unfortunately here there is no empirical base for calibration hence I present results for a baseline value of 0.2 and present sensitivity analysis using values of 0.3 and 0.1 as well.

\section{Results}

In this section I report the results of the simulation of the model. The main focus throughout the section will be on average conditional allocations to stock and their patterns over the life-cycle and by wealth levels. As a check on the model also average participation rates will be reported. To economize on space though I will omit participation rates by age and by wealth since those conform closely with what other models have found. The section is divided into two subsections. In the first one I report a benchmark case and, for comparisons, results of models that abstract from learning and from both learning and ambiguity but that are otherwise similar to the complete model in the choice of parameters. In this section the intuition behind the results will also be described. In the second subsection I report the results of a sensitivity analysis on several parameters to check the robustness of the findings of the model. 


\subsection{A Benchmark Case}

\subsubsection{The Model without Learning}

In this section I report the results that are obtained when learning is omitted from the model so that the extent of ambiguity that agents perceive in the stock return process is constant over time. Otherwise the model uses the same parameters as the baseline case with learning. The only other difference is that the per-period participation cost is set so as to obtain the same average participation rate as in the baseline case with learning. For exposition purposes I also report the results of a model that, keeping the same set of parameters, abstracts from ambiguity altogether and recalibrates the participation cost to get the same participation rate as the previous model.

The model with neither ambiguity nor learning can generate an average participation rate of 43.6 percent with a participation cost equal to about 11 percent of average annual earnings. Taking a rough estimate of the latter to be 35000 dollars implies a fixed cost of 3850 dollars per year. This cost is clearly huge and beside that the model generates an allocation to stocks for market participants of 99.7 percent. This result is not new and the intuition was well explained for example in Cocco, Gomes and Maenhout (2005): with stock returns uncorrelated with labor earnings the latter are a form of implicit holdings of a risk-free asset. Given this and the high equity premium households will want to invest almost entirely in risky stocks, hence the very high conditional stock share. On the other hand because of the large benefit of investing in the stock market, a large cost will be needed to deter agents from participating in it.

When ambiguity is added it is possible to obtain virtually the same partic- 
ipation rate - 43.7 percent — with a much smaller per period participation cost, that is, 0.7 percent of annual earnings. Again taking a reference value for average annual earnings of 35000 dollars this cost is equivalent to about 245 dollars. This number is reasonably small, although slightly larger than estimates provided by Paiella (2001) and Vissing-Jørgensen (2002) and ranging between 50 and 200 dollars. At the same time the model generates an allocation to stocks conditional on participation of about 58.2 percent a number close to the figures reported for example by Guiso et al. (2001). This result is obtained by assuming a "worst case" expected equity premium for a stock buyer of 0.9 percent. Since the relevant equity premium used by the agent in his optimal allocation problem is much lower this justifies the substantially smaller portfolio share of stocks. At the same time both the lower "worst case" equity premium, hence smaller perceived benefit of stock holding and the lower optimal share will enable a reasonably small per period participation cost to generate moderate participation rates as in the data.

Even though the model with ambiguity seems to provide a straightforward explanation for the moderate stock market participation rate and conditional stock shares one should check that this is obtained with a reasonable amount of ambiguity and that the model is consistent with other features of investors' behavior. With respect to the first issue one useful comparison can be drawn with the amount of uncertainty about the expected equity premium from a survey of finance professors reported in Welch (2000). This seems particularly appropriate in light of the experimental findings of Fox and Tversky (1995) that it is precisely when an agent knows that there are experts that are more knowledgeable than her on a subject that ambiguity aversion arises more strongly. The 
author interviewed 226 academic professors in finance asking among else to report a measure of the central tendency and 95 percent confidence interval of the arithmetic 30-year average of their equity premium forecast. He found the average central tendency was about 7 percent with the average confidence interval ranging from 2.2 to about 13 percent. If one interprets the 95 percent confidence interval as a plausible representation of the multiplicity of stock return distributions entertained by those academic professors the "worst case" equity premium would be 2.2 percent versus the 0.9 percent used in the current experiment. Also more than a tenth of the respondents considered as a "pessimistic scenario" an equity premium of 0 percent or less. Hence the number used here seems quite reasonable or even conservative, especially if one considers that it is reasonable to assume that a lay person faces more uncertainty about the expected equity premium than an academic professor in finance. A second argument can be developed along the lines of Jorion and Goetzmann (1999). The two authors claim that when we use the experience of the last century in the US to assess the equity premium we are actually conditioning on the experience of the most successful equity market in recent history. They compute return for other markets in the period 1921 to 1996 and find a median average return that is 3.5 percentage points below the one in the US with some countries without any mayor disruption in the functioning of the market — like Italy or New Zealand — at 4.5 percentage points below the US one. Something similar can be said for the US in previous times since according to Siegel (1992) the equity premium in the period 1802 to 1870 was only 1.5 percent, 6 and a half percentage points below the one in the period 1926 to 1990 . To the extent that investors are aware of this, assuming that they think that the "worst case" equity premium 


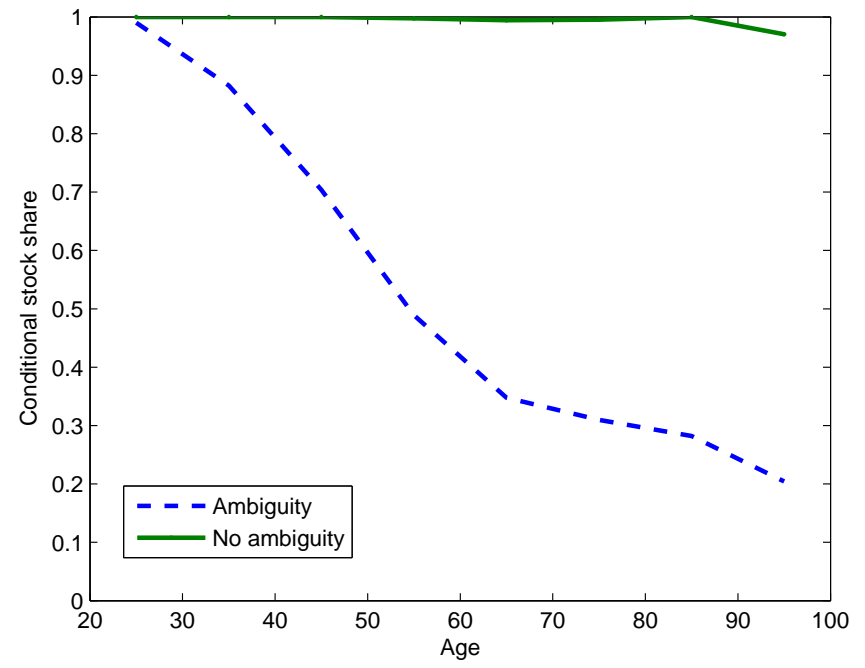

Figure 1: Life-Cycle profile of conditional stock shares, models without learning/ambiguity.

is 4.5 percent less than the true one, as it is done here, seems reasonable. Finally, a third argument is based on the well known fact that the average of a volatile series cannot be pinpointed with high precision unless a very long draw of data is available. For example Cochrane (1997) reports that with a 50 year long sequence of US data running from 1947 to 1996 the 95 percent confidence interval for the average equity premium is \pm 5 percent away from its 8 percent mean. Once again if we think about the 95 percent confidence interval as the set of plausible distributions, a "worst case" equity premium 4.5 percent below the true one as assumed here seems quite reasonable.

On the other test though the model fares quite worse. This can be seen with the help of Figure 1 where I report the life-cycle profiles of conditional allocations to stocks for both models considered in this section. The continuous line at the 
top represents the profile for the model without ambiguity and consistently with an overall average conditional share of 100 percent it is almost equal to that value at all ages. The dashed line represents instead the profile for the model with ambiguity. As it can be seen the conditional average allocation to stocks starts at 100 percent in the first decade of life and then monotonically declines to only 20 percent in the last decade of life. This profile is strongly at odd with the data where conditional shares tend to increase slightly early in the very first decade of life and then are virtually constant afterwards. Similar declining patterns have been found in other studies like Cocco, Gomes and Maenhout (2005) and Gomes and Michaelides (2005), especially during working life. Compared to those papers the decline in the model with ambiguity is quantitatively even stronger and persists all over the life-cycle. The intuition is that early in life the agent holds a large amount of relatively safe human capital and little financial wealth hence would like to invest the latter entirely in stocks to benefit from the equity premium. As it ages human capital gets progressively smaller and financial wealth accumulates inducing the agent to diversify towards safe bonds. After retirement the further path depends on whether wealth is drawn down more rapidly than the progressive reduction in the residual non financial wealth as the horizon shortens. While this intuition is common with the one in the models cited above, here the reduced perceived benefit of stock market participation associated with the "worst case" equity premium makes the decline in stock shares more substantial. Summarizing the assumption that the agent considers the stock return ambiguous and is averse to ambiguity helps generating moderate participation rates in the stock market and moderate portfolio allocations to stocks for participants but it does so at 
the cost of taking a step in the wrong direction as far as the life-cycle profile of conditional shares is concerned. Motivated by this finding in the next section I introduce learning in the model.

\subsubsection{The Baseline Model with Learning}

In this section I present the results of the model with learning in a multiple prior environment à la Epstein and Schneider (2005) described in the model section of this paper. The choice of parameters is the one described as the baseline case in the calibration section. Under that calibration the model produces an average participation rate of 43.1 percent and an average share invested in stocks for participants of 59.6 percent. Both figures are roughly consistent with the empirical evidence: the participation rate is a little below the most recent figures which are around 50 percent starting from the 1998 Survey of Consumer Finances and somewhat above the ones for the preceding years - they were at 40.4 percent in $1995 .{ }^{10}$ The conditional share was 59.4 percent in the 1998 SCF according to Guiso et al. (2001) and only slightly below that figure in the 1995 and 2001 SCF according to Heaton and Lucas (2000) and Gomes and Michaelides (2005) respectively. The life-cycle profile of conditional stock shares is reported in Figure 2. As it can be seen, when learning is allowed the strongly declining profile is overturned and substituted with an increasing profile that except for the first decade of life shows indeed a quite limited variation over the life-cycle. This brings the model predictions close to their empirical counterpart since in the data conditional stock shares tend to show little variation over age, with a small increase early in life. This is confirmed by Table 1 where I report

\footnotetext{
${ }^{10}$ The sources for these figures are the studies by Bertaut and Starr-McCluer (2000) and Guiso el al. (2001).
} 


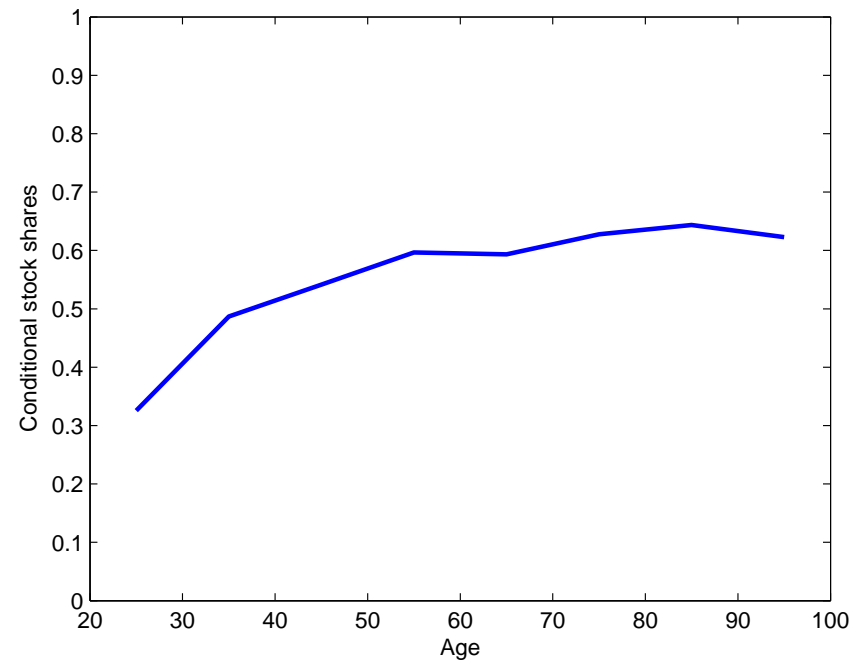

Figure 2: Life-cycle profile of conditional stock shares, baseline case.

Table 1: Conditional shares by age

\begin{tabular}{lcccccc}
\hline \hline & $20-30$ & $30-40$ & $40-50$ & $50-60$ & $60-70$ & $70+$ \\
\hline Data & 52.0 & 53.7 & 61.8 & 62.1 & 61.4 & 59.4 \\
Ambiguity & 98.9 & 88.2 & 70.4 & 48.9 & 34.8 & 30.5 \\
Learning & 32.6 & 48.7 & 54.1 & 59.7 & 59.3 & 63.2 \\
\hline \hline
\end{tabular}

the data underlying Figure 2 together with data from the US presented in Guiso et al. (2001). As we can see by comparing the first and last row of the table the life-cycle profile generated by the model tracks the empirical one quite closely from the second decade to the end of life and only underestimates it somewhat in the first decade of life. For comparison the second row reports also the profile for the model with ambiguity but not learning presented in the previous subsection. This profile is by contrast strongly monotonically decreasing and quite far from the empirical one also in quantitative terms. 


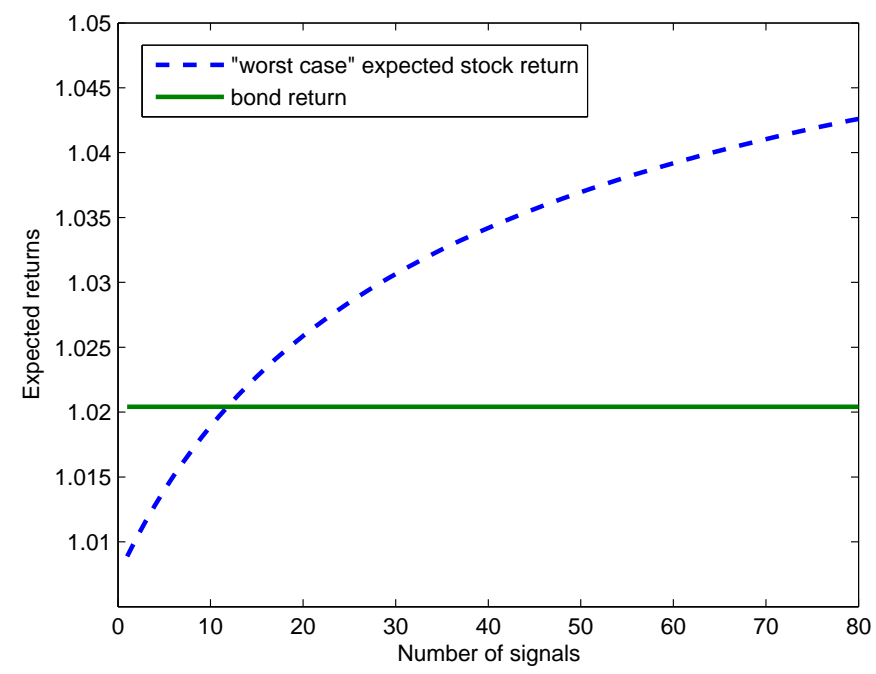

Figure 3: Worst case expected equity premium.

In order to develop the intuition to explain this result we can look at Figures 3 and 4 . The first of the two figures represents the "worst case" expected equity premium for a buyer as a function of the number of observations of the realized stock return assuming that these were 50 percent of the time high and 50 percent of the time low. In the same graph also reported by the flat continuous line is the return on the risk-free bond. As it can be seen the "worst case" equity premium moves from -1 percent for an agent with no prior observations of the realized returns to a little more than 2 percent for an agent that received the signal for almost all his life. This follows from the fact that as more and more signals reflecting the underlying process generating the stock returns are received, the set of possible distributions shrinks, hence the "worst case" expected equity premium increases. This is reflected in the decision rules presented in Figure 4. As an example the figure reports decision rules at ages 30, 40, 50, 
60 and 70 for an agent that participated in the stock market in every period and observed prior to each of those dates 50 percent of the times a high return realization and 50 percent of the times a low return realization. As one may see those decision rules are higher and higher as the agent gets older, hence had the time to observe more signals. Notice that the work of Cocco, Gomes and Maeanhout (2005) pointed out that in a conventional framework stock decision rules should move inwards as the agent ages to reflect the progressive reduction in relatively safe human wealth. While this phenomenon still exists in the current model, the shrinking of the posterior sets determines a counteracting force that overturns the age-decision rules relationship. Summarizing, along the life-cycle two forces would push the household towards a smaller exposition to stock market risk: one is the above mentioned reduction in the holdings of safe human wealth and the second is the progressive accumulation of wealth to finance retirement consumption - corresponding in the graph to a movement outwards along a given decision rule. On the other hand learning adds a force in the opposite direction given by the reduction in the posterior set and the ensuing improvement in the "worst case" equity premium. Overall as Figure 2 shows this turns the life-cycle profile of conditional stock shares into one that exhibits a mildly increasing pattern.

Finally we want once more to comment on the extent of ambiguity implied by the parameters chosen in this calibration of the model. We can see from figure 3 that starting from about 20 observations the "worst case" equity premium is about 1 percent and increases to a bit more than 2 percent after 70 observations. In light of the discussion in the previous section these numbers seem reasonable. In particular, they amount to say that after about 20 signals the 
agent uncertainty about the equity premium is only 1 percentage point larger than the average for academic professors in finance reported by Welch (2000) and that after a life of observations it becomes indeed smaller than that. As far as an agent with fewer than 10 years of observations on the stock return process are concerned the current parametrization entails a "worst case" equity premium that is negative. This can be justified in light of the results of field studies reported in Lusardi and Mitchell (2007). According to the authors in a survey conducted in Washington state it turned out that more than a third of the respondents did not know that over the past forty years stocks have outperformed bonds in term of returns. If we interpret this finding in terms of multiple priors this suggests that those households deem possible stock return distributions that entail a negative equity premium. ${ }^{11}$

\subsubsection{Conditional Shares by Wealth}

In this section I examine the results of the model with and without learning along another dimension, that is, the allocation to stocks for participants along the wealth distribution. This is done in Table 2. The table reports in the first row the empirical conditional stock shares by wealth quartiles and the top 5 percent of the distribution. The source for these data is Guiso et al. (2001) based on the 1998 edition of the Survey of Consumer Finances; the definition of stocks in

\footnotetext{
${ }^{11}$ Strictly speaking the question reported in Lusardi and Mitchell refers to knowledge of the historical record of the equity premium rather than long term forecasts so to make the statement reported in the text one needs to add that expectations are formed based on past observations. This assumption is consistent with the learning model used here. Moreover at the empirical level it is reasonable that the long term forecast of the equity premium reflects the long term historically recorded one. To support this just observe that the central tendency for the 30-year forecast of finance professors reported in Welch (2000) is about 7 percent, very close to historical records.
} 


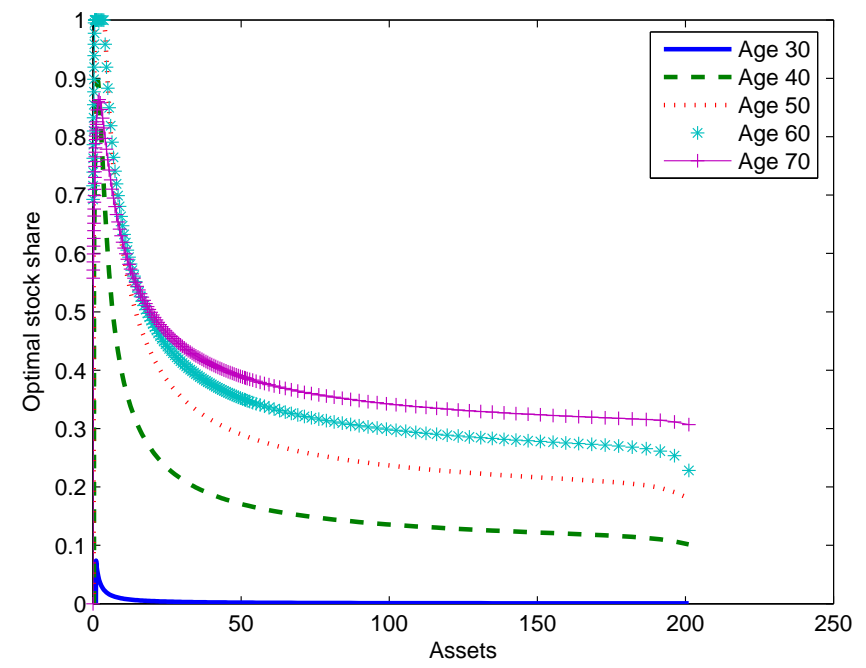

Figure 4: Stock portfolio decision rules.

their data includes both directly and indirectly held equity. In the second and third rows the corresponding figures from the model with ambiguity but not learning and for the baseline model with learning in ambiguous environment are reported. As we can see in the data the share of stocks conditional on participation is increasing over the whole wealth distribution. On the other hand the model without learning generates a very strongly negative relationship between wealth and conditional stock shares. As we can see the share allocated to the risky asset declines from virtually 100 percent to only 32.7 when moving from the bottom quartile to the top 1 percent of the wealth distribution. When learning is added to the model this declining pattern disappears and the share of assets invested in risky equity remains more or less constant over the whole distribution. Although this change is insufficient to match the data still it represents an important step in the right direction. 
Table 2: Conditional shares by wealth percentiles

\begin{tabular}{lccccc}
\hline \hline & Quartile I & Quartile II & Quartile III & Quartile IV & Top 5\% \\
\hline Data & 40.7 & 45.0 & 49.0 & 60.4 & 64.0 \\
Ambiguity & 99.9 & 99.7 & 75.4 & 41.3 & 32.7 \\
Learning & 57.0 & 56.7 & 61.3 & 60.3 & 58.5 \\
\hline \hline
\end{tabular}

To understand better where this result comes from in Table 3 we report the patterns of conditional stock shares by wealth levels but conditioning on age. This is done both for the model with ambiguity only and for the model with learning in a multiple prior framework. To keep the table at a manageable size the last two decades of life are not reported but their properties are similar to those of the nearby decades of life. What we can see from the table is that in the model with ambiguity only, if we condition on age, the patterns of equity shares by wealth are strongly monotonically decreasing: for example in the 40 to 50 age group the share declines from almost 100 percent to only about 40 percent and in the 60 to 70 age group it declines from about 72 percent to 26 percent. $^{12}$

If we then look at the bottom panel where the portfolio allocation in the model with learning is portrayed we see that while conditional on age the pattern of stock shares by wealth is still declining, it is much less so than in the model with ambiguity only. For example in the 40 to 50 year age group, when moving from the bottom quartile to the top 5 percent of the distribution, the decline in the conditional stock share is only from 61.7 percent to 47.7 percent and in the 60 to 70 year group it is from 66.8 percent to 51.7 percent. The ability

\footnotetext{
${ }^{12}$ The entries in the table marked with "n.a." correspond to age-wealth cells where the participation rate in the model is 0 so that a conditional equity share cannot be computed.
} 
Table 3: Conditional shares by wealth percentiles and age

\begin{tabular}{lccccc}
\hline \hline & Quartile I & Quartile II & Quartile III & Quartile IV & Top 5\% \\
\hline Ambiguity & & & & & \\
$20-30$ & n.a & n.a & n.a & 98.9 & 94.9 \\
$30-40$ & n.a & 99.9 & 99.6 & 81.7 & 58.0 \\
$40-50$ & 99.9 & 98.1 & 78.0 & 52.7 & 39.6 \\
$50-60$ & 98.9 & 67.9 & 49.1 & 37.5 & 30.7 \\
$60-70$ & 71.8 & 45.5 & 35.6 & 30.2 & 26.3 \\
$70-80$ & n.a & 37.1 & 33.4 & 29.5 & 26.7 \\
\hline Learning & & & & & \\
$20-30$ & 99.9 & 98.8 & 37.2 & 35.9 & 39.5 \\
$30-40$ & 65.9 & 51.3 & 50.5 & 49.1 & 47.0 \\
$40-50$ & 61.8 & 57.6 & 55.2 & 52.2 & 47.8 \\
$50-60$ & 67.5 & 63.5 & 60.2 & 55.8 & 50.8 \\
$60-70$ & 66.8 & 62.2 & 59.0 & 56.1 & 51.7 \\
$70-80$ & 68.2 & 65.5 & 63.6 & 60.5 & 57.2 \\
\hline \hline
\end{tabular}




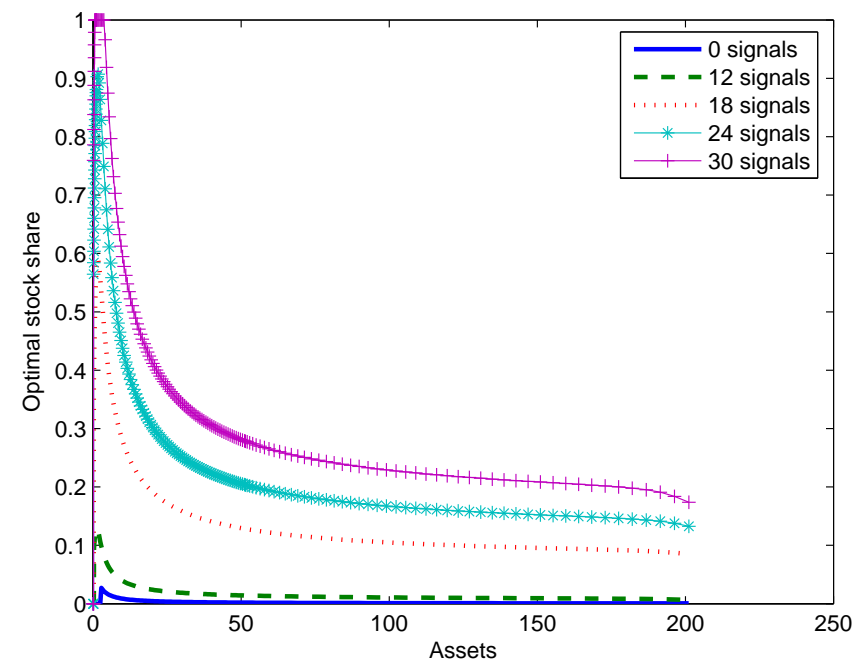

Figure 5: Stock portfolio decision rules.

of the model with learning to reduce the slope of the conditional share-wealth relationship can be understood by looking at Figure 5. This figure is similar to Figure 4 but it focuses on a household of a given age, more precisely, 50 years old and plots the optimal portfolio allocation as a function of the past number of signals about the stock return process observed prior to that age. As in the previous figure the decision rules reported here are plotted assuming a past fraction of high signals observed equal to 50 percent. As we can see these decision rules are declining in wealth as in more conventional models and decision rules corresponding to more observations are higher. This reflects the reduction in size of the set of posterior distributions that the agent deems possible as more signals that reflect the underlying data generating process accrue. In a more conventional model or in one with ambiguity only, for a given age the conditional stock share could only decline with the amount of asset 
holdings, reflecting movements to the right along a given curve. In a model with learning though a wealthier agent can potentially invest a larger fraction of her wealth in stocks than a poorer one. This is because a wealthier agent will have faced a better past history of labor shocks, hence may have started to participate in the stock market earlier and for this reason have observed more signals of the underlying return process. This corresponds to movements towards higher decision rules. Although this mechanism can potentially generate a positive relationship between wealth and stock shares for market participants conditional on age, what we see from Table 3 is that, at least with the set of parameters used here, quantitatively the model can take a step in the right direction by reducing the magnitude of the negative slope of that relationship but not overturn its qualitative pattern. Summarizing, the fact that the model is able to generate a relationship between conditional risky investment and wealth that is slightly increasing is in part the result of a less negatively sloped relationship conditional on age and in part the consequence of the reduction of conditional equity shares of young households, who hold little wealth, compared to older and wealthier ones.

\subsection{Sensitivity Analysis}

Summarizing the results of the two previous subsections we can say that a reasonable amount of uncertainty about the stock return process and ambiguity aversion enable an otherwise conventional life-cycle portfolio choice model to predict moderate participation rates and moderate conditional stock shares with low risk aversion and reasonably small participation costs. On the other hand they generate conditional stock shares that are strongly decreasing in both 
age and wealth moving a step in the wrong direction compared to a conventional model. Adding learning in this multiple prior environment, while preserving the ability of the model to generate moderate average participation rates and conditional shares, also enables it to produce a life-cycle profile of stock allocation for participants that is slightly increasing but with little variation as in the data. It also makes conditional stock investment roughly constant in wealth thus taking a step in the right direction towards matching the empirical evidence.

In choosing the parameters to calibrate the learning process I insured that the resulting amount of ambiguity perceived by agents over their life-cycle was reasonable. However in a dynamic context of learning it is not only the average extent of ambiguity that matters but also the way it unfolds over time. Since there is no hard evidence based on which one can fix the parameters that determine this property the only thing that can be done is to perform a sensitivity analysis. The present section is devoted to this task. As a side output this section will also help further understanding the mechanisms at work in the model. Beside the parameters related to learning the current section will perform a sensitivity analysis also on the coefficient of relative risk aversion.

Initial Ambiguity. In this first sensitivity analysis I change the size of the set of distributions of the stock return that the household includes in its beliefs at the beginning of life. I consider two cases: one with more ambiguity where the initial set of priors for the probability of a high stock return is the interval $[0.276,0.724]$ and one with less initial ambiguity where that set is the interval $[0.323,0.677]$. These imply an initial "worst case" equity premium of about -2 percent and -0.5 percent respectively. The remaining parameters are left un- 


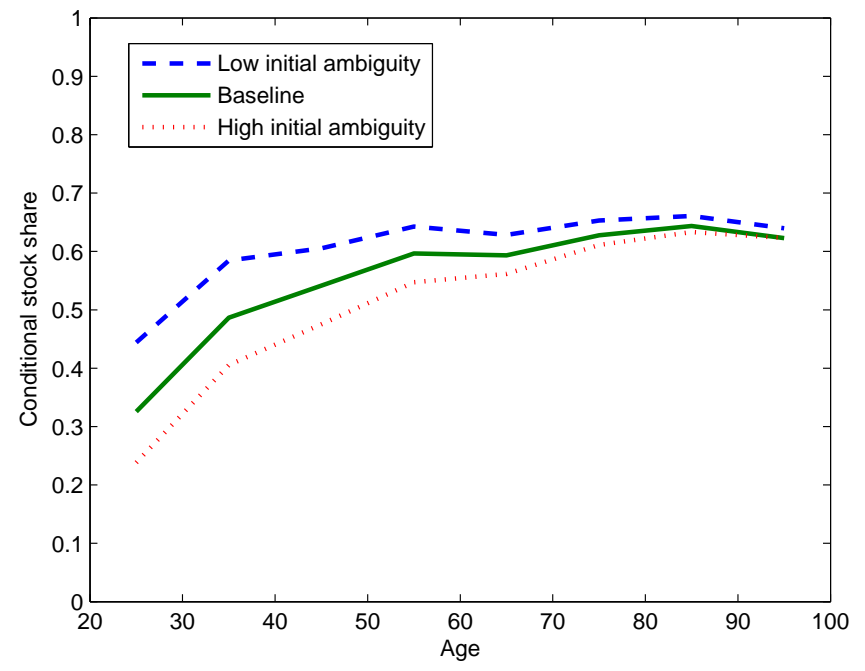

Figure 6: Life-cycle profile of conditional stock shares; changing initial ambiguity.

changed from the baseline case. The model with less initial ambiguity generates an average participation rate of 50.5 percent and an average share for participants of 64.6 percent. The model with higher initial ambiguity produces an average participation rate of 36.7 percent and a conditional allocation to stocks of 56.1 percent. As we can see the numbers are close to the data although the participation rate in the case of more initial ambiguity is somewhat below. The life-cycle profiles of conditional stock shares are reported in Figure 6. The figure also reports the same profile for the baseline case. As we can see the profile in the case of less initial ambiguity lies above and is flatter than the baseline case, while the life-cycle profile in the case of higher initial ambiguity lies below and is steeper. As a result they converge later in life. To understand this result observe that less initial ambiguity means a smaller set of beliefs at the beginning 
of life, hence the "worst case" expected equity premium starts out larger. This means that the benefits of stock holding are perceived to be larger. As a result more households will participate from the very beginning and they will invest larger shares of their wealth in the stock market. Also, since the evolution of the "worst case" equity premium tends to follow an asymptotic path, the initial differences in participation rates and conditional stock shares tend to vanish over the life-cycle.

"Speed" of Learning. In this paragraph the sensitivity analysis on the parameter $\alpha$ is performed. Two values are taken, that is, $\alpha=0.1051$ and $\alpha=$ 0.2991 and the remaining parameter that controls the properties of the evolution of the posterior set is changed so that the set itself at the beginning of life is unchanged. The wording "speed" of learning refers to the fact that $\alpha$ determines how strict is the statistical test based on which stock return distributions are discarded or kept in the set of beliefs in the face of new signals: a higher $\alpha$ implies a stricter test hence a quicker adaptation of beliefs to new signals. In the case of $\alpha=0.2991$ the average participation rate is 46.9 percent and the average equity share for participants is 68.6 percent, while in the case of $\alpha=0.1051$ the average participation rate is 30.8 percent and stock holding households invest on average 51.1 percent of their wealth in the risky asset. The life-cycle profiles of conditional stock shares are reported in Figure 7, where as usual, the continuous line reports the baseline case for comparison. Consistently with the overall average, the line representing the conditional share for the higher value of $\alpha$ lies above and the one for the lower value of $\alpha$ lies below the one of the baseline case. Also the profile for $\alpha=0.2991$ shows an increase from 50 percent 


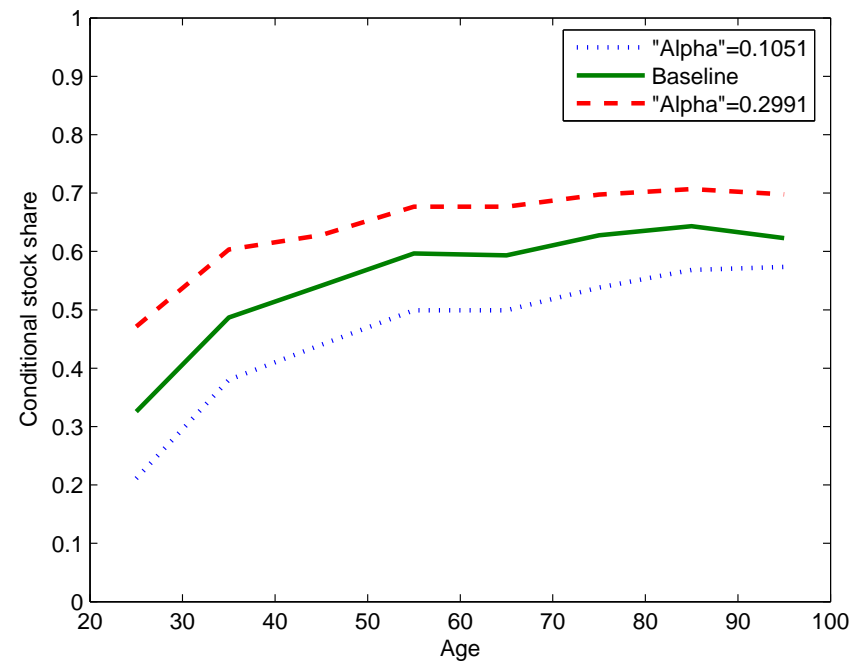

Figure 7: Life-cycle profile of conditional stock shares; changing the "speed" of learning.

to a little bit more than 60 percent between the first and the second decade of life and then little variation thereafter, while the profile for $\alpha=0.1051$ follows a steeper pattern especially in the first four decades of life. To understand this result observe that upon entry in the workforce in both cases agents face the same amount of ambiguity. After that in the model with larger $\alpha$ they update their beliefs more quickly which, on average, translates into better "worst case" expected equity premia. This is reflected both in the higher average participation rate and higher conditional stock share. Also since with larger $\alpha$ the household gets rid of ambiguity more quickly, apart from the first decade of life the life cycle profile of conditional stock shares shows a much weaker slope. 


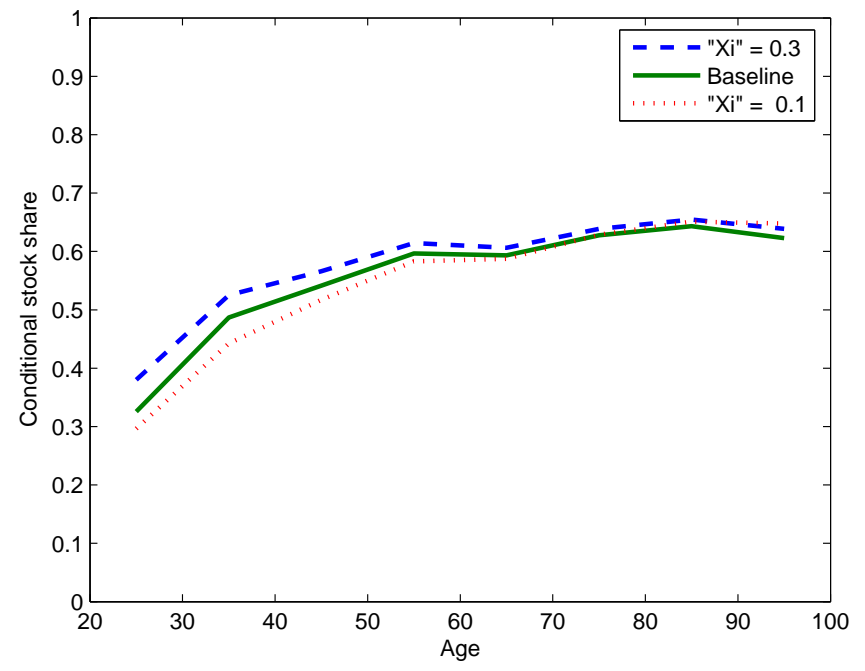

Figure 8: Life-cycle profile of conditional stock shares, changing the informational advantage of participants.

Informational Advantage of Participants. In this section I consider a further sensitivity analysis in which I change the probability that an agent that does not participate in the stock market receives the signal about the stock return process. In general, for a given "worst case" expected equity premium, the higher that probability the smaller is the relative benefit of participation compared to non participation. I consider two cases that move in opposite direction starting from the baseline case. When the probability $\xi$ that a nonstockholding household receives a signal is set at the higher value of 0.3 the average participation rate is 46 percent and the average conditional share is 62.6 percent, while when $\xi$ is equal to 0.1 the average participation rate is 39.8 percent and the average conditional share is 56.8 percent. The life-cycle profiles of conditional stock shares are reported in Figure 8. As we can see the two 
profiles are not very different from each other and from the baseline case. The life-cycle profile for $\xi=0.1$, that is, a lower probability of receiving a signal is only a little steeper since it starts about 7 percentage points below the one for $\xi=0.3$ and then converges to it at the end of life. The intuition for these results is the following: an increase in $\xi$ implies that a larger proportion of agents that do not find it optimal to participate in the stock market will receive the signal about the return process anyway. On average this will imply that over time their set of beliefs will shrink, hence the "worst case" expected equity premium improves. This may induce them to participate in the market earlier than they would have otherwise done. As a result the average percentage of participants in the population increases. At the same time, as agents start participating earlier, hence receive signals about the return process systematically from a younger age, this will lead to earlier reduction of ambiguity and the observed increase in the conditional share as well.

Risk Aversion. In this paragraph I explore the implications of changing risk aversion in the current model and consider two alternative values, that is, 1.5 and 3.5. In the low risk aversion case the average participation rate is 40.9 percent and the average conditional share is 74.3 percent; in the high risk aversion case the average participation rate is 41.9 percent and the average conditional share is 45.3 percent. The results concerning the conditional share are quite standard since it is well known that an increase in the risk aversion coefficient will cause the agent to reduce its exposition to the risky asset. As far as participation rates are concerned, earlier work like Gomes and Michaelides (2005) pointed out that an increase in risk aversion has two effects working in opposite 


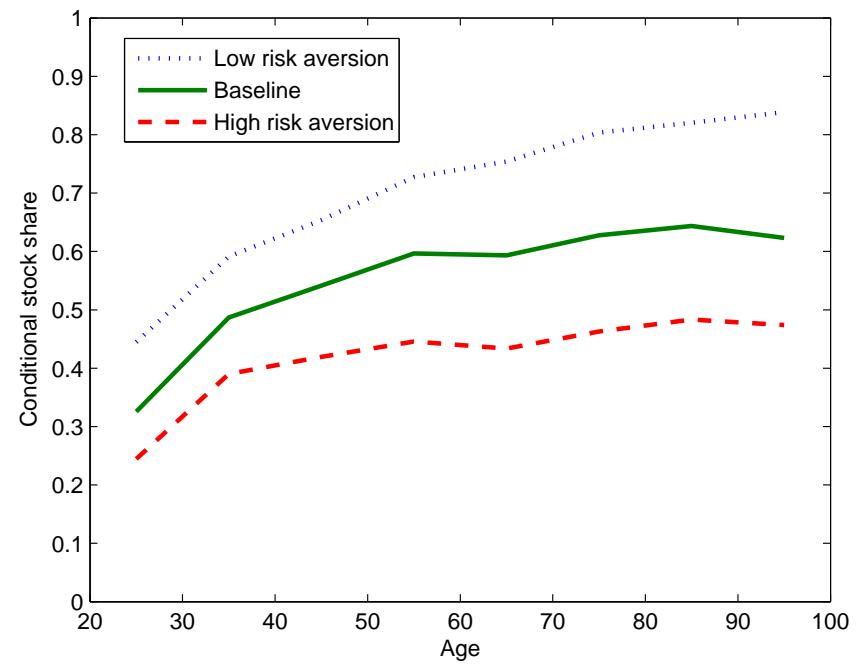

Figure 9: Life-Cycle profile of conditional stock shares; changing risk aversion.

directions. On the one hand the reduction in the conditional share would make agents less willing to pay the fixed participation cost thus reducing participation. On the other hand though, given the functional form chosen for the utility function a higher risk aversion is associated with more prudence inducing higher precautionary savings. This makes the agent more willing to pay the fixed cost, hence increase participation. In their model the overall effect is to increase the average participation rate while in the current model with ambiguity and learning the two forces approximately balance out leaving the average participation rate almost unaffected by the coefficient of risk aversion, at least for the range of values considered. This reflects the fact that the unitary benefit of investing in equity, which is driven by the "worst case" equity premium is smaller hence the change of the overall benefit is dampened. Results concerning the life-cycle profiles of conditional shares are reported in Figure 9 where the middle con- 
tinuous line again represents the baseline case and is reported for comparison. Qualitatively the patterns do not change with risk aversion: conditional shares are increasing and more than in the baseline case when the coefficient of relative risk aversion is 1.5 while they are virtually constant, except for the first decade of life when risk aversion is increased to 3.5 .

Sensitivity Analysis of Conditional Shares by Wealth. In this paragraph I summarize the results of the sensitivity analysis performed above but with respect to the pattern of conditional stock holdings as a function of wealth. In order to economize on space the tables with the conditional allocations to stock by wealth and age groups are not reported. ${ }^{13}$ The results of this analysis are reported in Table 4. A look at the table confirms the result of the baseline case that the patterns of conditional portfolio allocations by wealth do not exhibit the strongly declining shape of the model with ambiguity only or of a conventional model with sufficiently large risk aversion to generate reasonable average shares. Within this general observation there are some differences among the cases considered. For example some of the patterns are a little more increasing although still less than in the data. One is the case of $\alpha=0.2991$ where the conditional allocation to stocks moves from 59.6 percent in the bottom quartile of the wealth distribution to 71.3 percent in the third quartile to stay roughly constant thereafter. If we go back to Figure 7 we see that this case is also one where the life-cycle profile is flatter so that what we observe across wealth levels is least driven by young poor agents holding lower conditional shares. The main reason then is that conditional on age the relationship between wealth and portfolio share of stocks is less declining than in the baseline

${ }^{13}$ These tables are available from the author upon request. 
case. This can be explained by the fact that when $\alpha$ is higher learning occurs faster, hence the benefits in term of a smaller sets of posteriors for those who get the signals are larger. Wealthier agents in general start to participate earlier, get more signals hence benefit more from the faster reduction in ambiguity. A similar argument in the opposite direction explains why the case $\alpha=0.1051$ instead exhibits an overall declining pattern of conditional stock shares over the wealth distribution. The other case that shows a more pronounced increase in conditional stock shares over the wealth distribution is the one with $\xi=0.1$ where the conditional share moves from 39.2 percent in the bottom quartile to 61.4 percent in the top one and then only modestly declines to 59.7 percent in the top 5 percentiles of the distribution. The basic principle to interpret this result is the same as the one mentioned in the previous case: wealthier agents through the observation of signals can reduce the size of the belief set, hence increase "worst case" equity premium better than poorer agents. Here the reason is that given the lower probability of observing such signals for non participants the difference between wealthier agent who participate more often and poorer agents who participate less frequently becomes larger. Once again moving the parameter in the other direction $-\xi=0.3$ - leads to one of the most declining patterns.

\section{$5 \quad$ Summary and Conclusions}

In the present paper I have introduced ambiguity and learning in an ambiguous environment in an otherwise basic model of life-cycle portfolio allocation. It was shown that a plausible amount of ambiguity can rationalize moderate conditional stock shares and moderate participation rates, as observed in the 
Table 4: Conditional shares by wealth percentiles

\begin{tabular}{lccccc}
\hline \hline & Quartile I & Quartile II & Quartile III & Quartile IV & Top 5\% \\
\hline Baseline & 57.0 & 56.7 & 61.3 & 60.4 & 58.5 \\
\hline HIA & 58.3 & 52.4 & 56.6 & 57.3 & 56.6 \\
LIA & 61.1 & 62.9 & 67.3 & 64.1 & 60.5 \\
\hline$\alpha=0.1051$ & 61.1 & 50.8 & 51.9 & 50.2 & 48.1 \\
$\alpha=0.2991$ & 59.6 & 66.7 & 71.3 & 69.7 & 68.0 \\
\hline$\xi=0.1$ & 39.2 & 49.0 & 59.6 & 61.4 & 59.7 \\
$\xi=0.3$ & 70.3 & 62.8 & 63.3 & 60.9 & 58.6 \\
\hline$\sigma=1.5$ & 91.0 & 67.6 & 73.5 & 77.6 & 78.8 \\
$\sigma=3.5$ & 42.9 & 47.1 & 47.6 & 42.6 & 40.2 \\
\hline \hline
\end{tabular}

data, by resorting to relatively small fixed costs of participating in the stock market. Ambiguity alone though did not prove adequate to represent household behavior since it generated patterns of conditional stock shares that were counter-factually declining in both age and wealth. When learning is introduced the model, while still delivering moderate average participation rates and conditional stock shares for a wide range of parameters it also moves towards a better fit with the data along two dimensions. First it generates life-cycle profiles of conditional stock shares that are mildly increasing in age. Second, for some set of parameters it is also able to generate patterns of conditional stock holdings over the wealth distribution that are mildly increasing. This second result though is less robust to changes in key parameters. Also it is obtained in part by the reduction in conditional shares for young agents that are on average poorer, thus leaving the wealth-share relationship conditional on age still declining, albeit to a lesser degree than more conventional models or the model with 
ambiguity but without learning. As such in this dimension the current theory could be complemented by alternative models, like the non homothetic utility model presented in Wachter and Yogo (2008) to match the empirical evidence more closely. 


\begin{abstract}
Appendix
In this section I will briefly describe the numerical methods used to solve the model presented in the paper. The procedure requires two steps, that is, first solving the agent's dynamic programming problem and second simulating the model by using the decision rules obtained in the first step and draws of the realizations of the stock return and the individual histories of earnings and mortality shocks. Because of the minimization with respect to the set of beliefs the dynamic programming problem turns out to be more demanding than in a standard problem. In practice one has to compute the set of posteriors $\mathcal{M}_{t}$ and then choose the pairs $\theta \in \mathcal{M}_{t}$ and $\lambda \in[-\bar{\lambda}, \bar{\lambda}]$ that minimize maxima with respect to the distributions in the set of admissible beliefs. The computation of such set then requires the addition of two state variables that were labeled $\phi_{t}$ and $n_{t}$ in the text and that represent the total number of stock return realizations observed as signals of the underlying process and the fraction of those that were high. The assumption that short selling the stock was exogenously ruled out though, allows the model to retain tractability since under that assumption the minimizing distribution will be the one that minimizes the probability of a high stock return. The state space is discretized along the asset dimension using a grid of 165 points that is finer close to the origin and coarser away from it. The process for the labor earnings shock is also discretized by using 7 points and approximated with the method in Tauchen (1986). As far as $\phi_{t}$ and $n_{t}$ are concerned observe that in principle those are discrete variables. However the number of values they can take over a 80 year period — one like the lifespan — is very high. For this reason the value function was computed only on a subset of 11 points in each of those dimensions and interpolation was used elsewhere.
\end{abstract}


Functions were approximated via cubic splines along all the dimensions that required interpolation. The maximization with respect to stocks and bonds was performed using Brent's method: the method consists of bracketing the maximum with a triple, fitting a parabola through it and use it to eliminate the lowest point in the initial triple, then iterating until no further increase in the value of the function to optimize can be obtained. ${ }^{14}$ The method is repeated along each dimension — that is, each of the two assets — in turn by exploiting the relation $\max _{x, y} f(x, y)=\max _{x}\left\{\max _{y} f(x, y)\right\}$.

Once the decision rules are obtained the model is simulated. Multi-linear interpolation of the decision rules is used whenever the participation decision is the same at the 8 grid points defining a cube in the state space. Otherwise the optimal decision is recalculated using the value functions obtained in the previous step. This procedure is more accurate than simply applying multilinear interpolation in all cases, however it is also more time consuming. Also the computation of statistics by wealth levels is also somewhat time consuming. For this reason the simulation is done by considering a cohort of 1000 agents and repeating it 30 times. Results are obtained by averaging over the 30 repetitions. To insure robustness for some set of parameters the simulations were also repeated by doubling both the number of households and the number of repetitions. Results were always very similar to the ones obtained with fewer agents.

\footnotetext{
${ }^{14}$ See Brent (1973) for the theory and description of the method and Press et al. (1992) for the actual algorithm
} 


\section{References}

[1] Ameriks, John and Zeldes, Stephen. 2004. "How Do Household Portfolio Shares Vary with Age." Working Paper.

[2] Benzoni, Luca, Pierre Collin-Dufresne and Robert S. Goldstein Robert. 2007. "Portfolio Choice over the Life-Cycle in the Presence of 'Trickledown' Labor Income ". Working paper.

[3] Bertaut Carol C. and Starr-McCluer Martha. 2000. "Household Portfolios in the United States". Federal Reserve Board of Governors, Finance and Economics Discussion Paper: 26 (April).

[4] Brent R. 1973. "Algorithms for Minimization without Derivatives". Englewood Cliffs, NJ: Prentice-Hall.

[5] Cagetti Marco, Hansen Lars P., Sargent Thomas, Williams Noah. 2002. "Robustness and Pricing with Uncertain Growth". Review of Financial Studies. 15 (2). pp. 363-404.

[6] Calvet Laurent E., Campbell John Y. and Sodini Paolo. 2007. "Down or Out: Assessing the Welfare Costs of Household Investment Mistakes". Journal of Political Economy. 115 (5). pp. 707-747.

[7] Campanale Claudio, Castro Rui and Clementi Gianluca. 2007. "Asset Pricing in a Production Economy with Chew-Dekel Preferences". Working paper.

[8] Campbell John Y., Cocco Joao, Gomes Francisco and Maenhout Pascal. 1999. "Investing Retirement Wealth? A Life-cycle Model". Working paper, Harvard University. 
[9] Cao Henry H., Tang Tan and Zhang Harold H. 2005. "Model Uncertainty, Limited Asset Market Participation, and Asset Prices". Review of Financial Studies. 18 (4). pp. 1219-1251.

[10] Cecchetti Stephen G., Pok-Sang Lam and Nelson C. Mark. 2000. "Asset Pricing with Distorted Beliefs: Are Equity Returns too Good to be True ?". American Economic Review. 90. pp. 787-805.

[11] Cocco Joao; Gomes Francisco and Maenhout Pascal. 2005. "Portfolio Choice over the Life-Cycle". Review of Financial Studies, 18(2): 491-533.

[12] Cochrane John H. 1997. "Where Is the Market Going: Uncertain Facts and Novel Theories". Working paper 6207, NBER, (Cambridge, MA).

[13] Curcuru Stephanie, Heaton John, Lucas Deborah and Moore Damien. 2004. "Heterogeneity and Portfolio Choice: Theory and Evidence". Working Paper.

[14] Epstein, Larry G. and Schneider Martin. 2003. "Recursive Multiple Prior". Journal of Economic Theory. 113. pp. 1-31.

[15] Epstein, Larry G. and Schneider Martin, 2005, "Learning under Ambiguity". Working Paper.

[16] Epstein Larry G. and Wang Tan. 1994. "Intertemporal Asset Pricing under Knightian Uncertainty". Econometrica. 62 (3). pp. 283-322.

[17] Fox Craig R. and Tversky Amos. 1995. "Ambiguity Aversion and Comparative Ignorance". Quarterly Journal of Economics. 100 (3). pp. 585-603. 
[18] Garlappi Lorenzo, Uppal Raman and Wang Tan. 2006. "Portfolio Selection wtih Parameter Uncertainty: A Multi-Prior Approach". Review of Financial Studies. 20. pp. 41-81.

[19] Gilboa Itzach and David Schmeidler. 1989. "Maxmin Expected Utility with Non-unique Priors". Journal of Mathematical Economics. 18. pp 141-153.

[20] Gomes, Francisco and Michaelides Alexander. 2005. "Optimal Life-Cycle Asset Allocation: Understanding the Empirical Evidence". The Journal of Finance. 60(2): 869-904.

[21] Guiso L., Haliassos M. and Jappelli T. eds. 2001. "Household Portfolios". Cambridge and London: MIT press.

[22] Haliassos, Michael and Michaelides Alexander. 2003. "Portfolio Choice and Liquidity Constraints". International Economic Review. 44(1): 143-177.

[23] Hansen Gary D. 1993. "The Cyclical and Secular Behaviour of the Labour Input: Comparing Efficiency Units and Hours Worked". Journal of Applied Econometrics. 8(1): 71-80.

[24] Heaton John and Lucas Deborah. 1997. "Market Frictions, Savings Behavior, and Portfolio Choice", Macroeconomic Dynamics. 1: 76-101.

[25] Heaton John and Lucas Deborah. 2000. "Portfolio Choice in The Presence Of Background Risk", Economic Journal. 110: 1-26.

[26] Hubbard Glenn, Skinner Jonathan and Zeldes Stephen. 1994. "The Importance of Precautionary Motives in Explaining Individual and Aggregate Saving". Carnegie-Rochester Conference Series in Public Policy. 40: 59126. 
[27] Jorion Philippe and Goetzmann William N. 1999. "Global Stock Markets in the Twentieth Century". Journal of Finance. 54 (3). pp. 953-980.

[28] Ju Nengjiu and Miao Jianjun. 2007. "Ambiguity, Learning and Asset Returns". Working Paper.

[29] Klibanoff Peter, Marinacci Massimo and Mukerji Sujoy. 2006. "Recursive Smooth Ambiguity Preferences". Working Paper.

[30] Leippold Markus, Trojani Fabio and Vanini Paolo. 2007. "Learning and Asset Prices under Ambiguous Information". Review of Financial Studies. 20 (5). pp. 1-33.

[31] Lettau Martin. "Inspecting the Mechanism: Closed-form Solutions for Asset Prices in Real Business Cycle Models". The Economic Journal. 113 (July). pp. 550-575.

[32] Lusardi Annamaria and Mitchell Olivia S. 2007. "Financial Literacy and Retirement Preparedness: Evidence and Impications for Financial Education". Business Economics. January. pp. 35-44.

[33] Lynch Anthony W., and Sinan Tan. 2004. "Labor Income Dynamics at Business Cycle Frequencies: Implications for Portfolio Choice ". Working paper 11010, NBER (Cambridge, MA).

[34] Maenhout Pascal. 2004. "Robust Portfolio Rules and Asset Pricing ". Review of Financial Studies. 17 (4). pp. 951-983.

[35] Mankiw Gregory N., and Reis Ricardo. 2007. "Sticky Information in General Equilibrium". Journal of the European Economic Association. 5 (2-3). pp. 603-613. 
[36] Mehra Rajnish and Prescott Edward C. 1985. "The Equity premium: A Puzzle". Journal of Monetary Economics. 15. pp. 145-161.

[37] Paiella Monica. 2001. "Limited Financial Market Participation: A Transaction-Cost Based Explanation". The Institute for Fiscal Studies. WP $01 / 06$.

[38] Press William H., Flannery Brian P., Teukolsky Saul A., and Vetterling William T. 1992. "Numerical Recipes in Fortran 77: The Art of Scientific Computing". Cambridge University Press, (Cambridge, MA).

[39] Reis Ricardo. 2006. "Inattentive Consumers". Journal of Monetary Economics. 53 (8). pp. 1761-1800.

[40] Siegel Jeremy J. 1992. "The Equity Premium: Stock and Bond Returns since 1802". Financial Analyst Journal. 48 (1). pp. 28-38.

[41] Sims Christopher A. 2006. "Rational Inattention: A Research Agenda". working paper.

[42] Tauchen George. 1986. "Finite State Markov-Chain Approximations to Univariate and Vector Autoregressions". Economics Letters, 20. pp. 177181.

[43] Vissing-Jørgensen Annette. 2002. "Towards an explanation of household portfolio choice heterogeneity: Nonfinancial income and participation cost structures. ". Working paper 8884, NBER, (Cambridge, MA).

[44] Wachter Jessica A. and Yogo Motohiro. 2007. "Why Do Household Portfolio Shares Rise in Wealth". Working Paper. 
[45] Welch Ivo. 2000. "Views of Financial Economists on the Equity Premium and on Professional Controversies". The Journal of Business. 73 (4). pp.501-537. 
Our papers can be downloaded at:

http://cerp.unito.it/publications

\section{CeRP Working Paper Series}

\begin{tabular}{|c|c|c|}
\hline$N^{\circ} 1 / 00$ & Guido Menzio & Opting Out of Social Security over the Life Cycle \\
\hline $\mathrm{N}^{\circ} 2 / 00$ & $\begin{array}{l}\text { Pier Marco Ferraresi } \\
\text { Elsa Fornero }\end{array}$ & $\begin{array}{l}\text { Social Security Transition in Italy: Costs, Distorsions and (some) } \\
\text { Possible Correction }\end{array}$ \\
\hline$N^{\circ} 3 / 00$ & $\begin{array}{l}\text { Emanuele Baldacci } \\
\text { Luca Inglese }\end{array}$ & $\begin{array}{l}\text { Le caratteristiche socio economiche dei pensionati in Italia. } \\
\text { Analisi della distribuzione dei redditi da pensione (only available } \\
\text { in the Italian version) }\end{array}$ \\
\hline$N^{\circ} 4 / 01$ & Peter Diamond & Towards an Optimal Social Security Design \\
\hline$N^{\circ} 5 / 01$ & Vincenzo Andrietti & $\begin{array}{l}\text { Occupational Pensions and Interfirm Job Mobility in the } \\
\text { European Union. Evidence from the ECHP Survey }\end{array}$ \\
\hline$N^{\circ} 6 / 01$ & Flavia Coda Moscarola & $\begin{array}{l}\text { The Effects of Immigration Inflows on the Sustainability of the } \\
\text { Italian Welfare State }\end{array}$ \\
\hline $\mathrm{N}^{\circ} 7 / 01$ & Margherita Borella & $\begin{array}{l}\text { The Error Structure of Earnings: an Analysis on Italian } \\
\text { Longitudinal Data }\end{array}$ \\
\hline $\mathrm{N}^{\circ} 8 / 01$ & Margherita Borella & $\begin{array}{l}\text { Social Security Systems and the Distribution of Income: an } \\
\text { Application to the Italian Case }\end{array}$ \\
\hline$N^{\circ} 9 / 01$ & Hans Blommestein & $\begin{array}{l}\text { Ageing, Pension Reform, and Financial Market Implications in } \\
\text { the OECD Area }\end{array}$ \\
\hline$N^{\circ} 10 / 01$ & $\begin{array}{l}\text { Vincenzo Andrietti and Vincent } \\
\text { Hildebrand }\end{array}$ & $\begin{array}{l}\text { Pension Portability and Labour Mobility in the United States. } \\
\text { New Evidence from the SIPP Data }\end{array}$ \\
\hline $\mathrm{N}^{\circ} 11 / 01$ & $\begin{array}{l}\text { Mara Faccio and Ameziane } \\
\text { Lasfer }\end{array}$ & $\begin{array}{l}\text { Institutional Shareholders and Corporate Governance: The Case } \\
\text { of UK Pension Funds }\end{array}$ \\
\hline $\mathrm{N}^{\circ} 12 / 01$ & Roberta Romano & $\begin{array}{l}\text { Less is More: Making Shareholder Activism a Valuable } \\
\text { Mechanism of Corporate Governance }\end{array}$ \\
\hline $\mathrm{N}^{\circ} 13 / 01$ & Michela Scatigna & Institutional Investors, Corporate Governance and Pension Funds \\
\hline$N^{\circ} 14 / 01$ & Thomas H. Noe & Investor Activism and Financial Market Structure \\
\hline $\mathrm{N}^{\circ} 15 / 01$ & Estelle James & $\begin{array}{l}\text { How Can China Solve ist Old Age Security Problem? The } \\
\text { Interaction Between Pension, SOE and Financial Market Reform }\end{array}$ \\
\hline$N^{\circ} 16 / 01$ & $\begin{array}{l}\text { Estelle James and } \\
\text { Xue Song }\end{array}$ & $\begin{array}{l}\text { Annuities Markets Around the World: Money's Worth and Risk } \\
\text { Intermediation }\end{array}$ \\
\hline$N^{\circ} 17 / 02$ & $\begin{array}{l}\text { Richard Disney and } \\
\text { Sarah Smith }\end{array}$ & $\begin{array}{l}\text { The Labour Supply Effect of the Abolition of the Earnings Rule } \\
\text { for Older Workers in the United Kingdom }\end{array}$ \\
\hline$N^{\circ} 18 / 02$ & Francesco Daveri & $\begin{array}{l}\text { Labor Taxes and Unemployment: a Survey of the Aggregate } \\
\text { Evidence }\end{array}$ \\
\hline$N^{\circ} 19 / 02$ & $\begin{array}{l}\text { Paolo Battocchio } \\
\text { Francesco Menoncin }\end{array}$ & $\begin{array}{l}\text { Optimal Portfolio Strategies with Stochastic Wage Income and } \\
\text { Inflation: The Case of a Defined Contribution Pension Plan }\end{array}$ \\
\hline$N^{\circ} 20 / 02$ & Mauro Mastrogiacomo & Dual Retirement in Italy and Expectations \\
\hline $\mathrm{N}^{\circ} 21 / 02$ & $\begin{array}{l}\text { Olivia S. Mitchell } \\
\text { David McCarthy }\end{array}$ & Annuities for an Ageing World \\
\hline
\end{tabular}




\begin{tabular}{|c|c|}
\hline$N^{\circ} 22 / 02$ & $\begin{array}{l}\text { Chris Soares } \\
\text { Mark Warshawsky }\end{array}$ \\
\hline$N^{\circ} 23 / 02$ & Ermanno Pitacco \\
\hline $\mathrm{N}^{\circ} 24 / 02$ & $\begin{array}{l}\text { Laura Ballotta } \\
\text { Steven Haberman }\end{array}$ \\
\hline $\mathrm{N}^{\circ} 25 / 02$ & $\begin{array}{l}\text { Edmund Cannon } \\
\text { Ian Tonks }\end{array}$ \\
\hline $\mathrm{N}^{\circ} 26 / 02$ & E. Philip Davis \\
\hline $\mathrm{N}^{\circ} 27 / 02$ & Reinhold Schnabel \\
\hline$N^{\circ} 28 / 02$ & Luca Spataro \\
\hline $\mathrm{N}^{\circ} 29 / 02$ & Marco Taboga \\
\hline$N^{\circ} 30 / 03$ & $\begin{array}{l}\text { Bas Arts } \\
\text { Elena Vigna }\end{array}$ \\
\hline$N^{\circ} 31 / 03$ & Giacomo Ponzetto \\
\hline $\mathrm{N}^{\circ} 32 / 04$ & $\begin{array}{l}\text { Angelo Marano } \\
\text { Paolo Sestito }\end{array}$ \\
\hline$N^{\circ} 33 / 04$ & $\begin{array}{l}\text { Elsa Fornero } \\
\text { Carolina Fugazza } \\
\text { Giacomo Ponzetto }\end{array}$ \\
\hline$N^{\circ} 34 / 04$ & Chourouk Houssi \\
\hline$N^{\circ} 35 / 04$ & $\begin{array}{l}\text { Monika Bütler } \\
\text { Olivia Huguenin } \\
\text { Federica Teppa }\end{array}$ \\
\hline$N^{\circ} 36 / 04$ & Laurence J. Kotlikoff \\
\hline $\mathrm{N}^{\circ} 37 / 04$ & Jay Ginn \\
\hline$N^{\circ} 38 / 05$ & $\begin{array}{l}\text { Carolina Fugazza } \\
\text { Federica Teppa }\end{array}$ \\
\hline$N^{\circ} 39 / 05$ & Anna Rita Bacinello \\
\hline $\mathrm{N}^{\circ} 40 / 05$ & $\begin{array}{l}\text { Carolina Fugazza } \\
\text { Massimo Guidolin } \\
\text { Giovanna Nicodano }\end{array}$ \\
\hline$N^{\circ} 41 / 05$ & $\begin{array}{l}\text { Massimo Guidolin } \\
\text { Giovanna Nicodano }\end{array}$ \\
\hline $\mathrm{N}^{\circ} 42 / 05$ & $\begin{array}{l}\text { Margherita Borella } \\
\text { Flavia Coda Moscarola }\end{array}$ \\
\hline$N^{\circ} 43 / 05$ & $\begin{array}{l}\text { John Beshears } \\
\text { James J. Choi } \\
\text { David Laibson } \\
\text { Brigitte C. Madrian }\end{array}$ \\
\hline
\end{tabular}

Annuity Risk: Volatility and Inflation Exposure in Payments from Immediate Life Annuities

Longevity Risk in Living Benefits

Valuation of Guaranteed Annuity Conversion Options

The Behaviour of UK Annuity Prices from 1972 to the Present

Issues in the Regulation of Annuities Markets

Annuities in Germany before and after the Pension Reform of 2001

New Tools in Micromodeling Retirement Decisions: Overview and Applications to the Italian Case

The Realized Equity Premium has been Higher than Expected: Further Evidence

A Switch Criterion for Defined Contribution Pension Schemes

Risk Aversion and the Utility of Annuities

Older Workers and Pensioners: the Challenge of Ageing on the Italian Public Pension System and Labour Market

A Comparative Analysis of the Costs of Italian Individual Pension Plans

Le Vieillissement Démographique :

Problématique des Régimes de Pension en Tunisie

What Triggers Early Retirement. Results from Swiss Pension Funds

Pensions Systems and the Intergenerational Distribution of Resources

Actuarial Fairness or Social Justice?

A Gender Perspective on Redistribution in Pension Systems

An Empirical Assessment of the Italian Severance Payment (TFR)

Modelling the Surrender Conditions in Equity-Linked Life Insurance

Investing for the Long-Run in European Real Estate. Does Predictability Matter?

Small Caps in International Equity Portfolios: The Effects of Variance Risk.

Distributive Properties of Pensions Systems: a Simulation of the Italian Transition from Defined Benefit to Defined Contribution The Importance of Default Options for Retirement Saving Outcomes: Evidence from the United States 


\begin{tabular}{|c|c|}
\hline$N^{\circ} 44 / 05$ & Henrik Cronqvist \\
\hline$N^{\circ} 45 / 05$ & Claudio Campanale \\
\hline$N^{\circ} 46 / 05$ & $\begin{array}{l}\text { Annamaria Lusardi } \\
\text { Olivia S. Mitchell }\end{array}$ \\
\hline$N^{\circ} 47 / 06$ & $\begin{array}{l}\text { Michele Belloni } \\
\text { Carlo Maccheroni }\end{array}$ \\
\hline$N^{\circ} 48 / 06$ & $\begin{array}{l}\text { Onorato Castellino } \\
\text { Elsa Fornero }\end{array}$ \\
\hline$N^{\circ} 49 / 06$ & Mariacristina Rossi \\
\hline$N^{\circ} 50 / 06$ & $\begin{array}{l}\text { Andrea Buffa } \\
\text { Chiara Monticone }\end{array}$ \\
\hline$N^{\circ} 51 / 06$ & Giovanni Mastrobuoni \\
\hline$N^{\circ} 52 / 06$ & $\begin{array}{l}\text { Luigi Guiso } \\
\text { Tullio Jappelli }\end{array}$ \\
\hline$N^{\circ} 53 / 06$ & Giovanni Mastrobuoni \\
\hline$N^{\circ} 54 / 06$ & $\begin{array}{l}\text { Annamaria Lusardi } \\
\text { Olivia S. Mitchell }\end{array}$ \\
\hline$N^{\circ} 55 / 06$ & Antonio Abatemarco \\
\hline$N^{\circ} 56 / 07$ & $\begin{array}{l}\text { John A. Turner } \\
\text { Satyendra Verma }\end{array}$ \\
\hline$N^{\circ} 57 / 07$ & $\begin{array}{l}\text { Giovanni Mastrobuoni } \\
\text { Matthew Weinberg }\end{array}$ \\
\hline$N^{\circ} 58 / 07$ & $\begin{array}{l}\text { Elisa Luciano } \\
\text { Jaap Spreeuw } \\
\text { Elena Vigna }\end{array}$ \\
\hline$N^{\circ} 59 / 07$ & $\begin{array}{l}\text { Riccardo Calcagno } \\
\text { Roman Kraeussl } \\
\text { Chiara Monticone }\end{array}$ \\
\hline $\mathrm{N}^{\circ} 60 / 07$ & $\begin{array}{l}\text { Riccardo Cesari } \\
\text { Giuseppe Grande } \\
\text { Fabio Panetta }\end{array}$ \\
\hline $\mathrm{N}^{\circ} 61 / 07$ & Irina Kovrova \\
\hline$N^{\circ} 62 / 07$ & $\begin{array}{l}\text { Margherita Borella } \\
\text { Elsa Fornero } \\
\text { Mariacristina Rossi }\end{array}$ \\
\hline$N^{\circ} 63 / 07$ & Claudio Campanale \\
\hline$N^{\circ} 64 / 07$ & $\begin{array}{l}\text { Carlo Casarosa } \\
\text { Luca Spataro }\end{array}$ \\
\hline$N^{\circ} 65 / 07$ & Annamaria Lusardi \\
\hline
\end{tabular}

Advertising and Portfolio Choice

Increasing Returns to Savings and Wealth Inequality

Financial Literacy and Planning: Implications for Retirement Wellbeing

Actuarial Neutrality when Longevity Increases: An Application to the Italian Pension System

Public Policy and the Transition to Private Pension Provision in the United States and Europe

Examining the Interaction between Saving and Contributions to Personal Pension Plans. Evidence from the BHPS

Do European Pension Reforms Improve the Adequacy of Saving?

The Social Security Earnings Test Removal. Money Saved or Money Spent by the Trust Fund?

Information Acquisition and Portfolio Performance

Labor Supply Effects of the Recent Social Security Benefit Cuts: Empirical Estimates Using Cohort Discontinuities

Baby Boomer Retirement Security: The Roles of Planning, Financial Literacy, and Housing Wealth

On the Measurement of Intra-Generational Lifetime Redistribution in Pension Systems

Why Some Workers Don’t Take 401(k) Plan Offers: Inertia versus Economics

Heterogeneity in Intra-Monthly Consumption. Patterns, SelfControl, and Savings at Retirement

Modelling Stochastic Mortality for Dependent Lives

An Analysis of the Effects of the Severance Pay Reform on Credit to Italian SMEs

La Previdenza Complementare in Italia:

Caratteristiche, Sviluppo e Opportunità per i Lavoratori

Effects of the Introduction of a Funded Pillar on the Russian Household Savings: Evidence from the 2002 Pension Reform

Does Consumption Respond to Predicted Increases in Cash-onhand Availability? Evidence from the Italian "Severance Pay"

Life-Cycle Portfolio Choice: The Role of Heterogeneous UnderDiversification

Rate of Growth of Population, Saving and Wealth in the Basic Life-cycle Model when the Household is the Decision Unit

Household Saving Behavior: The Role of Literacy, Information and Financial Education Programs

(Updated version June 08: “Financial Literacy: An Essential Tool for Informed Consumer Choice?”) 


\begin{tabular}{|c|c|c|}
\hline$N^{\circ} 66 / 07$ & $\begin{array}{l}\text { Maarten van Rooij } \\
\text { Annamaria Lusardi } \\
\text { Rob Alessie }\end{array}$ & Financial Literacy and Stock Market Participation \\
\hline$N^{\circ} 67 / 07$ & $\begin{array}{l}\text { Carolina Fugazza } \\
\text { Maela Giofré } \\
\text { Giovanna Nicodano }\end{array}$ & International Diversification and Labor Income Risk \\
\hline$N^{\circ} 68 / 07$ & $\begin{array}{l}\text { Massimo Guidolin } \\
\text { Giovanna Nicodano }\end{array}$ & Small Caps in International Diversified Portfolios \\
\hline$N^{\circ} 69 / 07$ & $\begin{array}{l}\text { Carolina Fugazza } \\
\text { Massimo Guidolin } \\
\text { Giovanna Nicodano }\end{array}$ & Investing in Mixed Asset Portfolios: the Ex-Post Performance \\
\hline$N^{\circ} 70 / 07$ & $\begin{array}{l}\text { Radha Iyengar } \\
\text { Giovanni Mastrobuoni }\end{array}$ & $\begin{array}{l}\text { The Political Economy of the Disability Insurance. Theory and } \\
\text { Evidence of Gubernatorial Learning from Social Security } \\
\text { Administration Monitoring }\end{array}$ \\
\hline$N^{\circ} 71 / 07$ & Flavia Coda Moscarola & $\begin{array}{l}\text { Women participation and caring decisions: do different } \\
\text { institutional frameworks matter? A comparison between Italy } \\
\text { and The Netherlands }\end{array}$ \\
\hline $\mathrm{N}^{\circ} 72 / 08$ & $\begin{array}{l}\text { Annamaria Lusardi } \\
\text { Olivia Mitchell }\end{array}$ & Planning and Financial Literacy: How Do Women Fare? \\
\hline$N^{\circ} 73 / 08$ & $\begin{array}{l}\text { Michele Belloni } \\
\text { Rob Alessie }\end{array}$ & $\begin{array}{l}\text { The Importance of Financial Incentives on Retirement Choices: } \\
\text { New Evidence for Italy }\end{array}$ \\
\hline$N^{\circ} 74 / 08$ & Maela Giofré & $\begin{array}{l}\text { Information Asymmetries and Foreign Equity Portfolios: } \\
\text { Households versus Financial Investors }\end{array}$ \\
\hline$N^{\circ} 75 / 08$ & $\begin{array}{l}\text { Harold Alderman } \\
\text { Johannes Hoogeveen } \\
\text { Mariacristina Rossi }\end{array}$ & $\begin{array}{l}\text { Preschool Nutrition and Subsequent Schooling Attainment: } \\
\text { Longitudinal Evidence from Tanzania }\end{array}$ \\
\hline$N^{\circ} 76 / 08$ & $\begin{array}{l}\text { Riccardo Calcagno } \\
\text { Elsa Fornero } \\
\text { Mariacristina Rossi }\end{array}$ & $\begin{array}{l}\text { The Effect of House Prices on Household Saving: The Case of } \\
\text { Italy }\end{array}$ \\
\hline$N^{\circ} 77 / 08$ & $\begin{array}{l}\text { Giovanni Guazzarotti } \\
\text { Pietro Tommasino }\end{array}$ & $\begin{array}{l}\text { The Annuity Market in an Evolving Pension System: Lessons } \\
\text { from Italy }\end{array}$ \\
\hline$N^{\circ} 78 / 08$ & $\begin{array}{l}\text { Margherita Borella } \\
\text { Giovanna Segre }\end{array}$ & $\begin{array}{l}\text { Le pensioni dei lavoratori parasubordinati: prospettive dopo un } \\
\text { decennio di gestione separata }\end{array}$ \\
\hline$N^{\circ} 79 / 08$ & Annamaria Lusardi & $\begin{array}{l}\text { Increasing the Effectiveness of Financial Education in the } \\
\text { Workplace }\end{array}$ \\
\hline$N^{\circ} 80 / 08$ & Claudio Campanale & Learning, Ambiguity and Life-Cycle Portfolio Allocation \\
\hline
\end{tabular}

